\section{COMBUSTION AND FUEL CHARACTERIZATION OF COAL-WATER FUELS}

\author{
Volume 4 \\ Commercial Scale Atomizer and
}

Prepared by

Combustion Engineering, Inc.

Windsor, Connecticut 06095

Project Manager

M. J. Hargrove

July, 1987

Prepared for

U.S. Department of Energy

Pittsburgh Energy Technology Center Under Contract DE-AC 22-82 PC 50271 


\section{Table of Contents}

Section

Title

Page ivumber

I

INTRODUCTION

1

Multiple Burner Design Test Program

4

I I

BURNER SELECTION

4

I I I

REFERENCE CWF ANALYSIS

IV

PRELIMINARY PERFORMANCE OBJECTIVES

V

RELATIVE ATOMIZER PERFORMANCE (COLD FLOW)

VI

COMPARATIVE COMBUSTION PERFORMANCE OF EACH GENERIC BURNER SYSTEM

Multiple CWF Forinulation Test Program

VII

BURNER SELECTION FOR $50 \times 10^{6}$ BTU/HR

33

VIII

LABORATORY ANALYSIS OF TEST CWFS

35

IX

ATOMIZATION CHARACTERIZATION

44

$X$

COMBUSTION CHARACTERIZATION

50

XI SUMMARY OF TASK 4 RESILTS

62

$X I I$

REFERENCE:

70 


\section{LIST OF TABLES}

Table No. Title

1

2

3

4

5

6
REFERENCE CWF DATA

SPRAY QUALITY OBSERVATIONS

SUMMARY OF LABORATORY FUEL ANALYSIS

SUMMARY OF COMBUSTION TEST RESULTS

AT OPTIMUM CARBON CONVERSION EFFICIENCY CONDITIONS

${ }^{N O}{ }_{X}$ EMISSIONS

BURNER PERFORMANCE SUMMARY
Page No

12

19

37

52

61

63 


\section{List of Fiqures}

Figure Number

Title

Page Number

High Swirl Wall-Field Burner

6

"Y" Jet CWF Atomizer

Refractory Chamber Burner

Refractory Chamber Burner CWF Atomizer

Tangential Firing Burner

Refractory Register Burner

Refractory Register Burner CWF Atomizer

Atomizer Test Facility

Comparative Atomization Results

Droplet Velocity vs. Droplet Diameter

Industrial Scale Burner Test Facility

Comparative Combustion Results

$50 \times 10^{6} \mathrm{Btu} / \mathrm{hr}$ HSWF Burner

Comparison of the Coal Particle Size

Distribution for the Five CWFs Tested

39

Comparison of Volatile Matter

40

Comparison of Ash Content

40

Comparison of High Shear Viscosity

43

Comparison of CWF Viscosity vs. Temperature

45

Comparison of Mass Median Diameter vs.

Atomizing Medium to Fuel Ratio at 100\% Load.

48

Spray Droplet Size Distribution at 100\% Load.

49

Percent Carbon Conversion vs. Percent Excess

Air at $100 \%$ Load.

Percent Carbon Conversion vs. Spray Droplet

Mass Median Diameter at 100\% Load. 57

Scanning Electron Micrograph of Flyash

48

\section{5}


I. INTRODUCTION

Recently the technology of coal-water fuel (CWF) combustion has advanced from fundamental laboratory and small-scale combustion studies to the study of large-scale practical combustors. A number of organizations have carried out many experimental studies on CWF in pilot to industrial scale combustion systems. These experiments have included work performed by government, industrial, and academic laboratories. Some of the fundamental studies have broadened the basic data base on CWF technology, while several larger scale demonstration programs have begun to advance the commercialization of this technology. However, most of the commercialization studies have been too limited in scope to allow the private sector to fully assess the potential for widespread utilization of CWF as an alternative to conventional fuel oils or natural gas. On the practical side, for the successful commercialization of CWF technology in the boiler marketplace, it is important that CWF can be produced, handled, and combusted in a cost effective manner in industrial scale syst ms.

The U.S. Department of Energy, Pittsburgh Energy Technology Center, entered into a CWF research contract with Combustion Engineering, Inc. in 1982. The program, entitled "Combustion and Fuel Characterization of Coal-Water Fuels" (Contract DE-AC22-82 PC 50271), was a multiple phase, multi-year effort with the overall objective of establishing a broad, commercially useable engineering data base for CWF technology. The data generated as a result of the contract would allow the private sector to make decisions on the technical, economic, and environmental feasibility of using CWF as a prime alternative fuel. The study also intended to provide the incentive for the private sector to continue and expand the development of stable, cost effective CWFs which can be transported, stored, and distributed the same way as conventional fuel oils, and which will burn reliably with minimum pollutant emissions. 
The program was structured into three major projects that addressed both utility and industrial applications:
1. CWF Combustion Characteristics
2. CWF Rheology
3. Plant Equipment Selection and Performance

The first two projects were conducted by a team from Combustion Engineering (C-E) and Gulf Research and Development Company (GRDC). The third was carried out by TRW.

The CWF Combustion Characteristics phase embodied multiple tasks which focused on key aspects of CWF combustion properties. This report summarizes studies conducted under Task 4 of the subject program. The overall objective of Task 4 was to quantify CWF atomization and combustion properties utilizing industrial/utility scale equipment.

Task 4 was broken down into two major phases of study. The first phase involved the selection and detailed performance characterization of several commercially available burners designed for use with CWF. Burners were comparatively evaluated with a single CWF reference formulation, using both cold flow atomization testing and combustion performance testing. These comparative burner tests were conducted at a scale of 25 million Btu/hr heat input.

The second phase of study under Task 4 focused on identifying combustion performance differences between various commercially oriented CWF formulations. A suitable burner design from the first phase of study under Task 4 was selected and scaled up to a $50 \times 10^{6}$ $\mathrm{Btu} / \mathrm{hr}$ heat input rating for use as a reference test bed for comparatively evaluating the atomization and combustion properties of five different CWF formulations. 
This report (Volume 4) provides a general overview of Task 4 and it's principal results and conclusions. Other information regarding technical approaches, test equipment, test procedures, test data and analyses relating to the remaining aspects of the work from each individual task are provided in the following volumes:

$\begin{array}{lll}\text { Volume 1 - All Tasks: } & \text { Final Summary Report } \\ \text { Volume 2 } & \begin{array}{l}\text { Task 1 and } \\ \text { Task 3 }\end{array} & \begin{array}{l}\text { Selection and Procurement of } \\ \text { Candidate Coal-Water Fuels with } \\ \text { Commercial Potential }\end{array} \\ \text { Volume 3 - Task 2: } & \begin{array}{l}\text { Bench-Scale Characterization of } \\ \text { Chemical, Physical and Combustion } \\ \text { Properties of Coal-Water Fuels }\end{array} \\ \text { Volume 5 - Task 5: } & \begin{array}{l}\text { Pilot-Scale Ash Deposition and } \\ \text { Performance Testing of Coal-Water } \\ \text { Fuels }\end{array} \\ \text { Volume } 6- & \text { Task 6: } & \begin{array}{l}\text { Commercial Application and } \\ \text { Economics of Coal-Water Fuels }\end{array}\end{array}$




\section{Multiple Burner Design Test Program}

I1. BURNER SELECTION

Burner designs evaluated under the first phase of Task 4 were selected based on manufacturers' current market share, suppliers' manufacturing capabilities, and previous experience with slurry fuels. A burner's impact on project budget and test schedule was al so considered in making the final decision on burner selection. Selected burner designs were required to comply with the following guidelines in order to ensure that the candidate CWF burners were commercially viable and could be installed in C-E's test furnace:

Capacity $-25 \times 10^{6}$ Btu/Hr Heat Input

Atomizing Air Temperature - ambient

Atomizing Steam/Air Pressure - less than 250 psig

Atomizing Steam Temperature - no greater than $20^{\circ} \mathrm{F}$ of superheat (i.e., $425^{\circ} \mathrm{F} \odot 250 \mathrm{psig}$ )

Atomizing Steam/Air Mass Flowrate - less than 700 1bs/hr

Burner Register Pressure Drop - less than 16" water column (W.C.) @ $600^{\circ} \mathrm{F}$

Burner Ignition Energy Requirements - less than $5 \times 10^{6} \mathrm{Btu} / \mathrm{hr}$ Heat Input

Flame Diameter - less than $8 \mathrm{ft}$

Flame Length - less than $12 \mathrm{ft}$ 
Burner Register Diameter - less than $5 \mathrm{ft}$

Burner Register Depth - (i.e., depth of windbox) - less than $4 \mathrm{ft}$

Requests for test burners were sent to sixteen manufacturers, and nine proposals were recelved. The nine proposals represented a wide range of burner register and atomizer design concepts.

Four burner designs were finally selected from the group of nine potential candidates; the four burners selected represented four unique design approaches. The burners, described in the following section, are referred to by code in order to preserve the anonymity of the participating burner manufacturers.

HIGH SWIRL WALL-FIRED BURNER

The design of this burner features a central prinary air register, which houses a primary air swirler through which a portion of the combustion air is passed (Figure 1). This swirling air exits the burner register through a refractory lined divergent exit nozzle. The primary air register is centrally located within an annular secondary air register through which the remainder of the combustion air is passed. This air register is equipped with co-rotational swirl vanes, which impart additional swirl to the total combustion air flow.

The atomizer for this burner is of the air-assisted, "Y - jet" type, specifically developed for CWF firing (Figure 2). The fuel stream is directed into a pressurized air stream. The shear forces which develop at the fuel/air interface initiate fuel stream atomization. The atomizer features tungsten carbide inserts in critical wear areas to extend atomizer 1 ife and maintain s.pecified performance. 


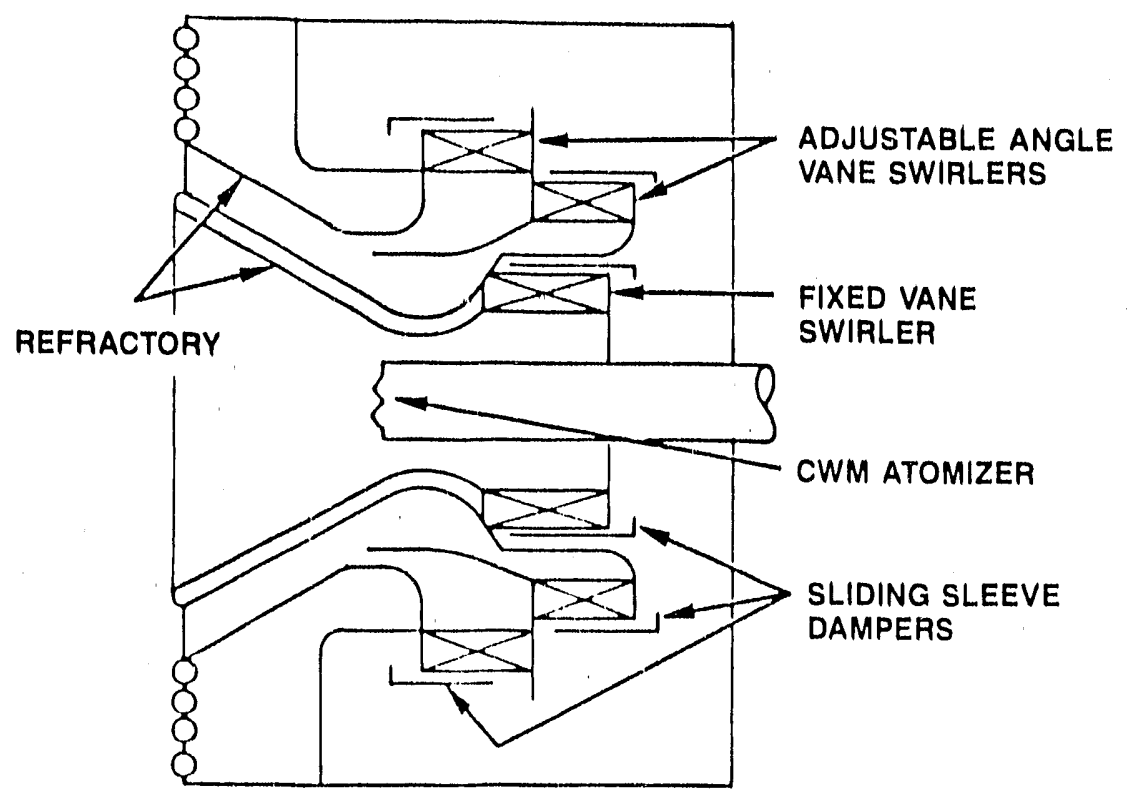

FIGURE 1: SCHEMATIC OF HIGH SWIRL WALL-FIRED BURNER

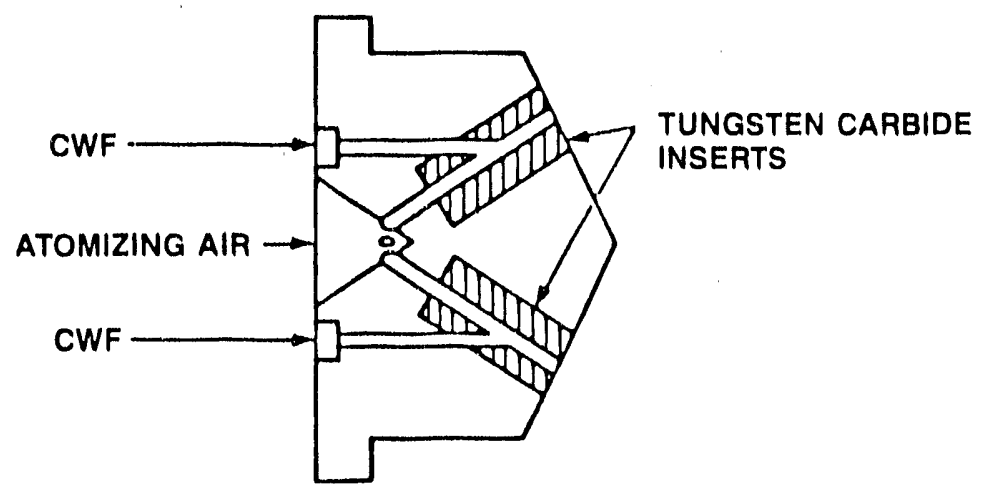

FIGURE 2: "Y” JET ATOMIZER 
The refractory chamber burner's design (Figure 3) features swirled primary combustion air in the refractory lined combustion chamber. A portion of the primary air passes through a centrally located vane swirler into the combustion chamber. The remainder of the primary air passes through a series of "tunnels" between the primary air register and the combustion chamber. These "tunnels" are angled such that they impart additional swirl to what can be referred to as secondary combustion air. Additional combustion air is added downstream to help complete combustion.

The atomizer for this burner is of the external mix, air assisted variety. Pressurized air is directed radially inward towards a central fuel stream. Shear forces at the fuel/air interface initiate atomization of the fuel stream. A general schematic of this atomizer is shown in Figure 4.

TANGENTIAL FIRING BURNER

This burner is a swirl stabilized unit configured for tangential corner firing (Figure 5 ). The principal elements of the burner are: a refractory-lined divergent nozzle, a fixed vane tangential swirler through which the primary combustion air stream is passed and secondary combustion air nozzles above and below the burner through which the balance of the combustion air is ducted (unswirled). The atomizer for this burner is of the air-assisted " $Y$-jet" type and was identical to the atomizer used in the HSWF burner (Figure 2). 


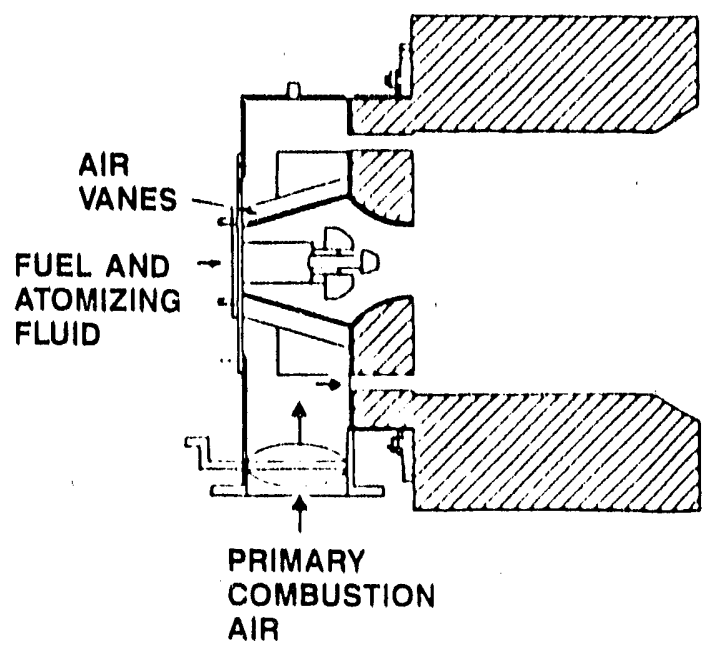

FIGURE 3: SCHEMATIC OF REFRACTORY CHAMBER BURNER

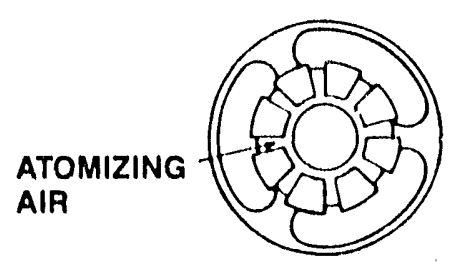

FRONT VIEW

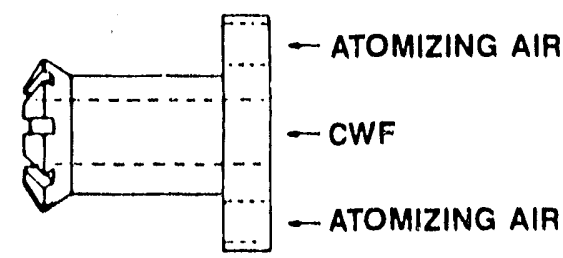

SIDE VIEW

FIGURE 4: CWF ATOMIZER 


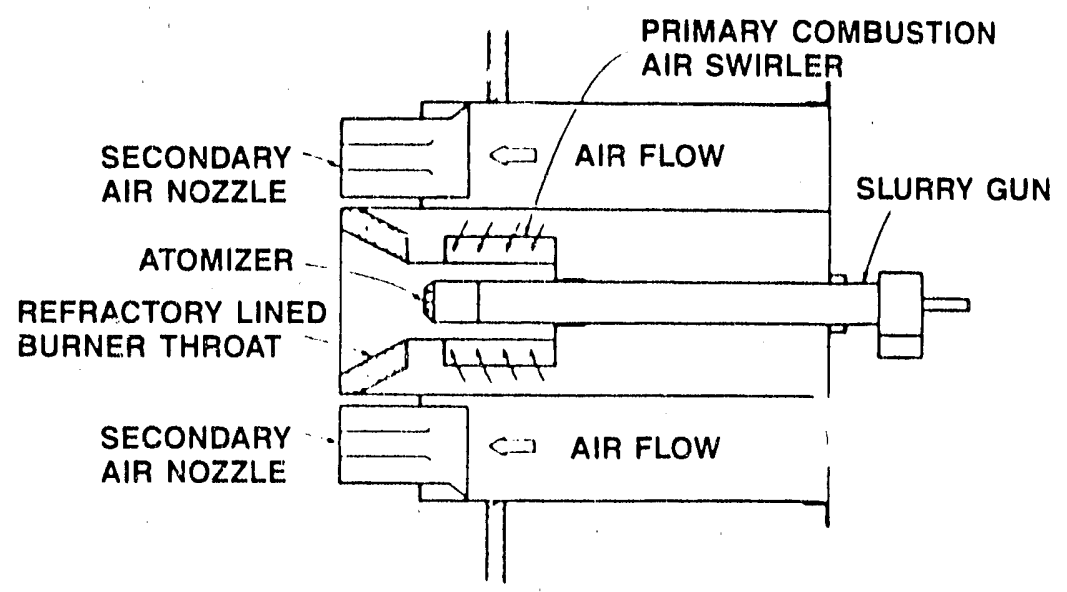

FIGURE 5: SCHEMATIC OF TANGENTIALLY FIRED BURNER 


\section{REFRACTORY/REGISTER BURNER}

The refractory/register burner (Figure 6) utilizes a single air plenum for its source of combustion air. Primary air passes through an adjustable angle vane swirler, into the register tunnel and out through a refractory quarl. Secondary air is added through an annulus around the burner quarl. A slotted metal cone located on the end of the CWF gun acts as a bluff body to help stabilize the flame. The atomizer for this burner is of the air-assisted "Y-jet." variety (Figure 7 ). 


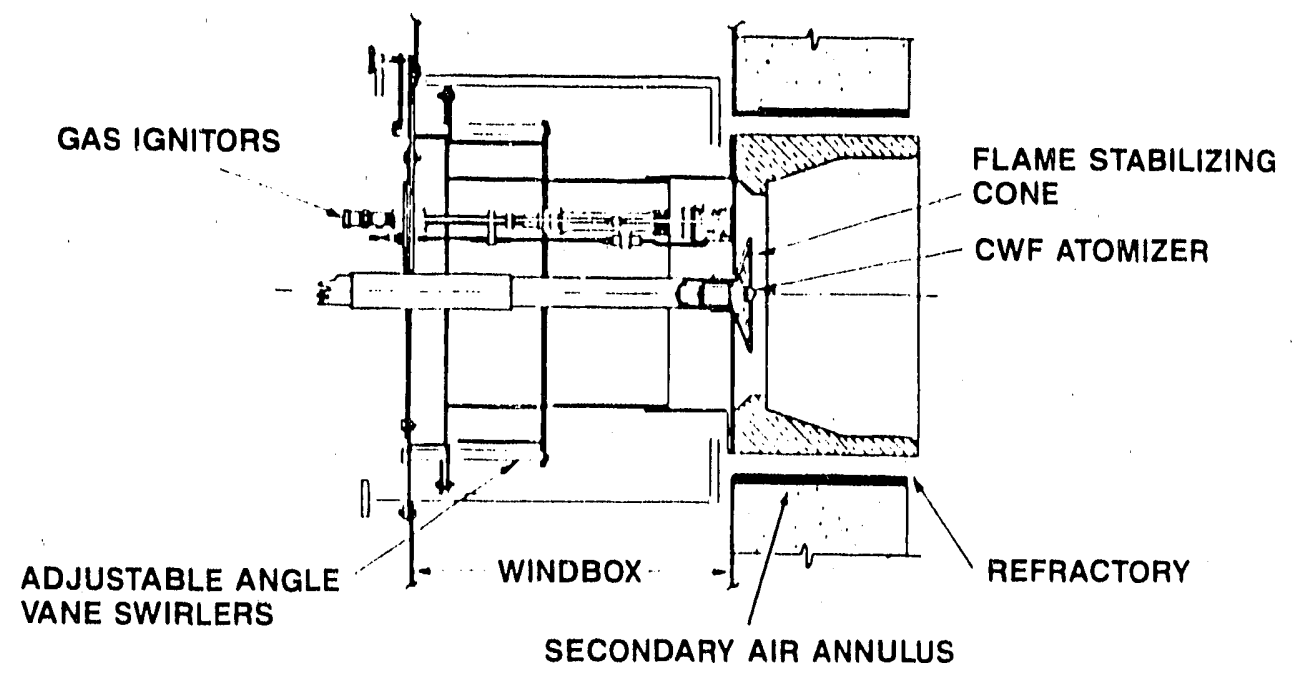

FIGURE 6: SCHEMATIC OF REFRACTORY/REGISTER BURNER

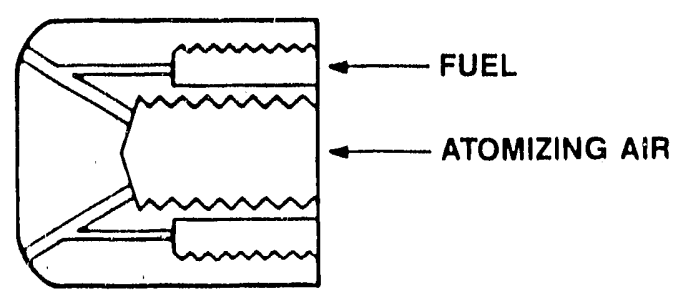

FIGURE 7: REFRACTORY REGISTER BURNER CWF ATOMIZER 
In order to obtain performance data that could be directly compared, each burner was tested with a reference CWF that was produced with the same coal by an established fuel manufacturer. The coals considered for this baseline fuel were all high-volatile, low sulfur bituminous coals from the Eastern United States. Splash Dam coal mined in Buchanan County, Virginia and beneficiated to $5.5 \%$ by weight ash was selected and used to produce all 90,000 gallons of the reference CWF used in the program.

The analysis of the Splash Dam coal is typical of high volatile eastern bituminous coals. Volatile matter content of the fuel was approximately $29 \%$ on a dry basis. The CWF had a solids loading of approximately $70 \%$ and a higher heating value of $10,145 \mathrm{Btu} / \mathrm{lb}$. Additional properties of the reference CWF are summarized below:

TABLE 1

REFERENCE CWF DATA

As-Received $\quad$ Dry Basis

Proximate, Wt \%

Moisture (Total)

29.5

Volatile Matter

20.7

29.4

Fixed Carbon (Diff.)

45.9

65.1

Ash

3.9

$+5.5$

Total

100.0

100.0

HHV, Btu/Ib

10,145

14,390 
TABLE 1 (CONTINUED)

\section{As-Received}

Dry Basis

Ultimate, Wt \%

$\begin{array}{lrr}\text { Moisture (Total) } & 29.5 & - \\ \text { Hydrogen } & 3.5 & 5.0 \\ \text { Carbon } & 57.4 & 81.4 \\ \text { Sulfur } & .8 & 1.1 \\ \text { Nitrogen } & 1.1 & 1.6 \\ \text { Oxygen (Diff.) } & 3.8 & 5.4 \\ \text { Ash } & 3.9 & 5.5 \\ & 100.0 & 100.0\end{array}$

CWF Screen Analysis

$\begin{array}{cc}+60 \text { mesh }(2501) & 0.1 \% \\ 60 \times 100 \text { mesh }(250 \times 1501 \mathrm{~m}) & 0.9 \% \\ 100 \times 200 \text { mesh }(150 \times 751 \mathrm{~m}) & 3.8 \% \\ 200 \times 325 \text { mesh }(75 \times 451 \mathrm{~m}) & 8.9 \%\end{array}$

Coal Particle Mass Median

Diameter $(1 \mathrm{~m}) \quad 15$

(1) Viscosity $100 \mathrm{sec}^{-1} \quad 640$ centipoise

(1) Power Law Exp. 1.4

(2) Viscosity $01100 \mathrm{sec}^{-1} \quad 983$ centipoise

(2) Viscosity o $2000 \mathrm{sec}^{-1} \quad 1700$ centipoise

(2) Viscosity $04000 \mathrm{sec}^{-1} \quad 2850$ centipoise

(3) Viscosity $1100 \mathrm{sec}^{-1} \quad 1250$ centipoise

(3) Viscosity $01500 \mathrm{sec}^{-1} \quad 2137$ centipoise

Density $\quad 1.21$ grams/cubic centimeter

Note:

(1) Rotational Viscometer $20^{\circ} \mathrm{C}$

(2) Extrusion Rheometer 0 Room Temp.

(3) Variable High Shear Viscometer $068-75^{\circ} \mathrm{F}$ 
IV. PRELIMINARY PERFORMANCE OBJECTIVES (PPOS)

C-E defined Preliminary Performance Objectives (PPOs) in order for the burner manufacturers to have consistent performance targets. The goal throughout the burner test program was to objectively compare designable performance characteristics to actual burner performance. The PPOs were as follows:

Combustion air preheat temperature: less than $500^{\circ} \mathrm{F}$

Excess combustion air requirements: 1ess than $40 \%$ @ $100 \%$ load

Turndown without support fuel: greater than $4: 1$

Ignition requirements: less than $20 \%$ of ful1 load heat input in a cold boiler for 30 minutes

Carbon conversion efficiency: greater than $98 \%$ at $100 \%$ load

Confirmed scanner signal over turndown range

No excessive burner coking during 8 hour test

No atomizer pluggage during 8 hour test

Atomized spray droplet mass median diameter should be less than 200 microns e $100 \%$ load

Atomizer assist fluid consumption: less than $0.25 \mathrm{lbs} / 1 \mathrm{~b}$ of fuel at $100 \%$ load

Windbox air pressure: less than 16 inches WC $100 \%$ load 
The comparative burner test program was initiated following identification of participating burner designs and performance targets. The first set of tests, described in this section, centered on quantifying the performance of each burner's CWF atomizer. Since it is generally accepted that atomization quality highly influences CWF combustion properties, tests were conducted in order to identify spray quality differences between each generically different atomizer design.

CWF spray droplet size has been shown to have a direct impact on CWF ignition properties. CWF devolatilization and ignition is delayed in proportion to the time required for droplet heating and drying. since droplet heating and drying times can increase exponentially with spray droplet diameter (1) it is vital that spray droplet diameters be minimized in order to improve CWF ignition characteristics.

CWF spray droplet diameter can also influence combustion in terms of carbon conversion efficiency. Several studies have indicated that coal particles contained within an atomized CWF droplet tend to agglomerate during drying and devolatilization and produce a single char particle proportional in size to the original droplet diameter (2). The carbon burnout time required for a given char particle is proportional to its diameter (3). It therefore appears that spray droplet size can directly influence carbon conversion efficiency by influencing the timeframe required for complete char particle combustion.

All tests were conducted in C-E's Atomizer Test Facility (ATF). A schematic of the facility is shown in figure 8 . The facility is uniquely configured to obtain spray droplet size distribution and droplet ballistics (velocity and trajectory) information. The facility operates in a cold flow (non-combustion) mode and can be 


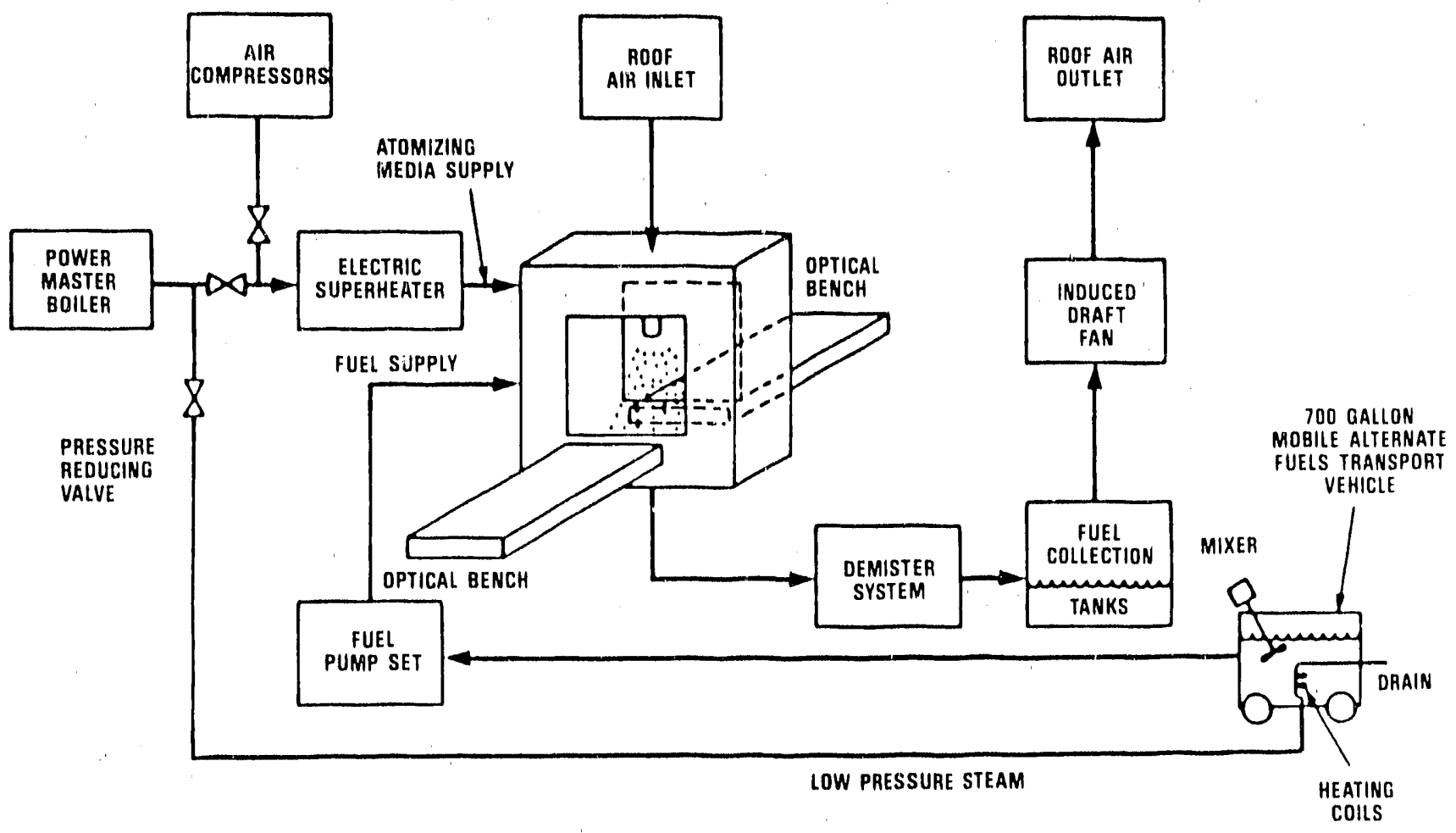

FIGURE 8: ATOMIZER TEST FACILITY 
used to quantify any atomizer's performance. The facility has been integral to research programs at $C-E$ which have resulted in levelopment of optimized atomizers for use in CWF burners, residual oil burners, and emissions control (dry scrubber) systems.

Two non-intrusive, optically based techniques are employed in the ATF to quantify spray quality. A laser diffraction based instrument (Malvern 2600) is used to determine spray droplet size distribution. Droplet size distribution can be determined using either Rosin-Rammler model based software or model-independent algorithms. The Rosin-Rammler software was exclusively emplcyed during the subject test program. Size distribution histograms were summarized and reported in terms of spray droplet mass median diameter (MMD) and the weight percentage of droplets which exceeded 300 microns in diameter. These comparatively large diameter droplets are believed to have a negative impact on both CWF ignition and carbon conversion, based on pulverized coal firing practices (4). Many investigators believed that minimizing the population of droplets exceeding 300 microns in diameter can improve CWF ignition and carbon conversion efficiency.

A high speed, double image photographic technique was also employed in the ATF in order to characterize differences in spray droplet ballistics between the generically different test atomizers. A stroboscopic light source, capable of producing two intense, short duration (one microsecond), light flashes, is used to illuminate an area of interest in the atomizer's spray. Using a high resolution, short depth of field ( 6 millimeter) camera, double exposure shadow graphic images of the droplets are recorded. Measurements of the time delay between flashes as well as measurements of the distance between double exposure droplet images are used to determine droplet velocity. Droplet trajectories are readily determined by observing the flight path of the droplets with respect to the camera's orientation. 
The ATF and the optical diagnostic techniques used by C-E are described in detail in Reference 5. All of the atomizers tested in this program were of the twin-fluid air-assisted type. Twin fluid atomizers utilize the energy contributed by the atomizing flutd to initlate breakup of the fuel stream into more readily coinbustible droplets. The quantity and/or quality of the atomizing medium defines the total energy avallable to initiate atomization and strongly influences generated spray quality. The quantity of atomizing media used is normaliy reported as the ratio of atomizing media to fuel $(A / F)$ mass flow ratio. The following summarized how influential $A / F$ mass flow ratio is on each respective CWF atomizer design.

Table 2 outlines spray quality observations made as a result of this test program. Al1 three of the atomizers tested met the PPO criteria of less than 200 microns MMD at an $A / F$ ratio of less than 0.25 . However, there were significant differences in spray quality and fuel and air pressures between atomizers. Overa11, the HSWF atomizer produced significantly finer sprays at any given $A / F$ ratio. For example, at an $A / F$ ratio of 0.20 , the HSWF atomizer produced an MMD of about 60 microns while the REF and REF/REG atomizer produced MMD's of 145-155 microns (Figure 9). Similar although less pronounced trends are shown in the 50\% and $25 \% 10$ ad curves (Figures 10 and 11).

Table 2 also summarizes droplet top size information derived from droplet size distribution data for each atomizer tested. As can be seen in the table, at $100 \% 10 a d$, the HSWF/TAN atomizer produced negligible $(<1 \%)$ droplets above 300 microns, while the REF and REF/REG atomizers produced $5.5 \%$ to $8.7 \%$, and $14 \%$ to $18 \%$, respectively, in the greater than 300 micron range. Similar trends can be seen in the data presented for 50\% and 25\% 10ads. This data correlates directly with the combustion results, as will be discussed later. 

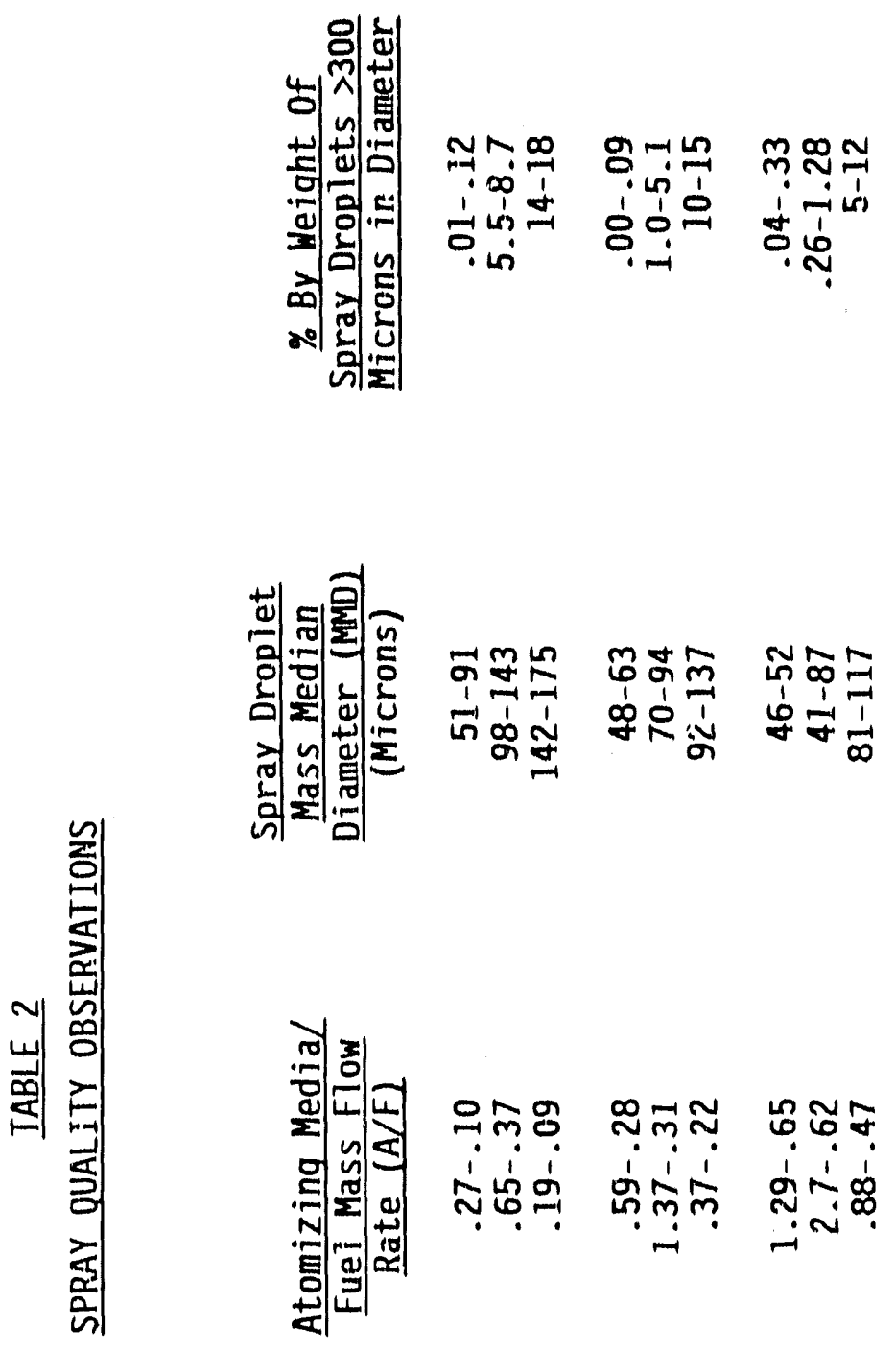

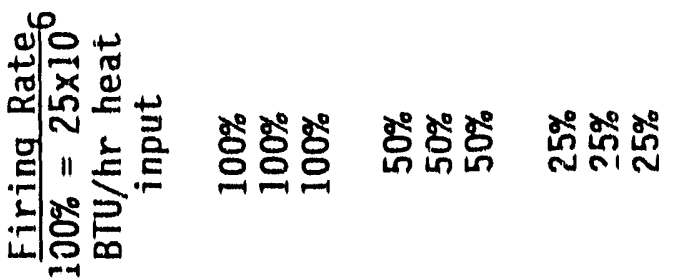

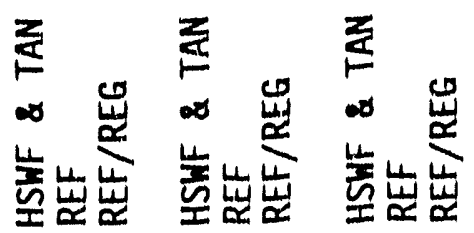



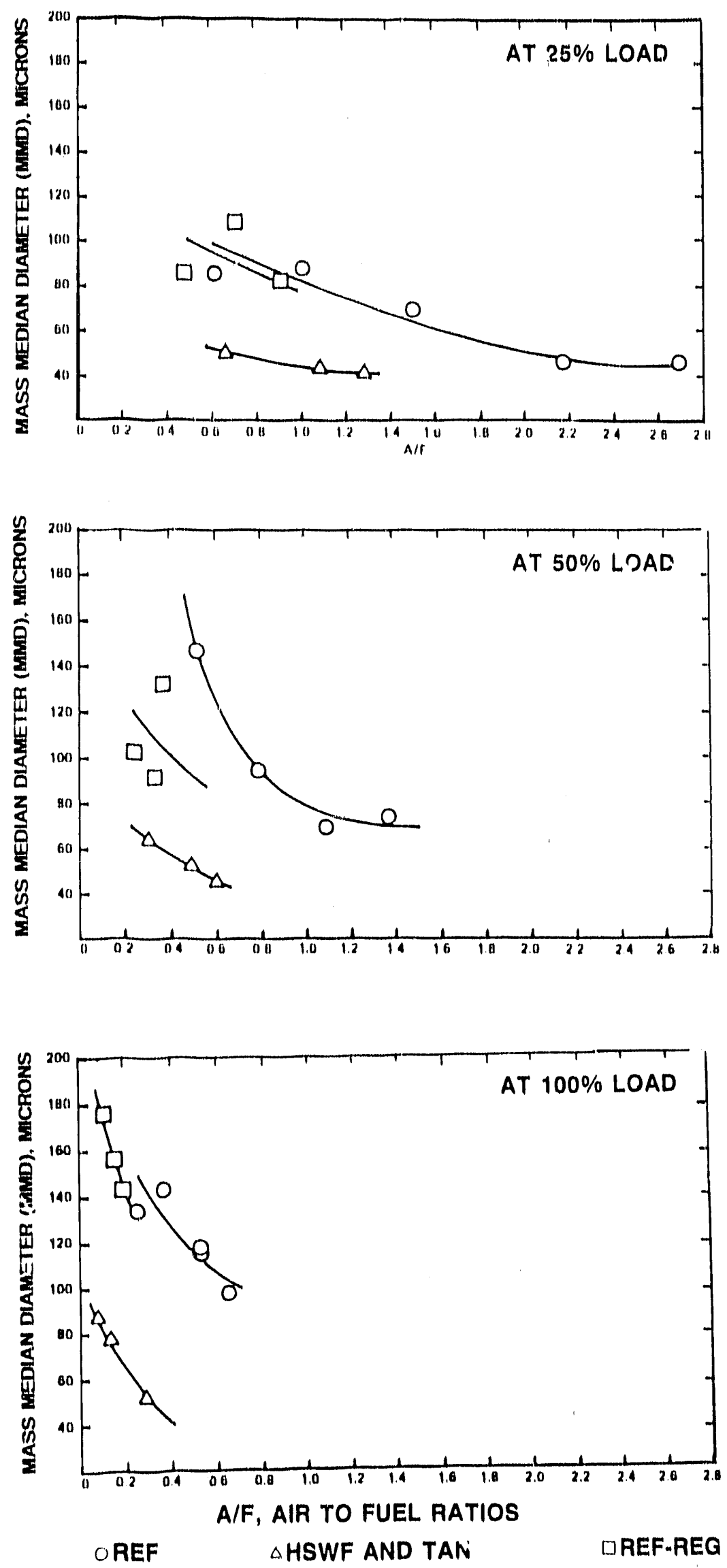

FIGUAE 9 COMPARISON OF MASS MEAN DIAMETER VERSUS ATOMIZING MEDIA/FUEL (A/F) MASS FLOW RATIOS FOR CWF BURNERS 


\section{Droplet Ballistics}

As previously mentioned, a high speed, double exposure photographic system was employed in the ATF in order to quantify relative differences, if any, in spray droplet ballistics between the gener!c atomizer designs. Photographs were taken of the spray at a location 24" axially downstream of the atomizer. Sampling at this location assured that complete atomization (1.e., the formation of spherical droplets from fragmented fuel ligaments) was achieved before the photographic sampling volume. The sampling location was also identical to that used for definition of the CWF spray droplet size distribution using the laser diffraction technique.

The photographic technique used permitted the determination of droplet velocity as a function of droplet diameter. Definition of the droplet size/velocity relationship is important for defining the near-burner aerodynamics required for effective combustion. Burner aerodynamics can, tn a certain extent, be adjusted to accommodate high velocity droplets by increasing the size or strength of the combustion air recirculation zone. Carbon burnout and burner ignition stability can be favorably influenced by minimizing the number of high momentum droplets which move rapidly out of the burner's primary aerodynamic recirculation zone.

Figure 10 summarizes diameter vs. velocity information obtained for the HSWF, TAN, and REF atomizers. In general, detected droplet velocities ranged between 2-13 meters/sec; the REF atomizer tended to generate somewhat higher velocities on average. This could possibly be attributed to the fact that the REF atomizer's operating $A / F$ ratio was over twice that of the HSWF/TAN atomizer ( 0.5 vs. $0.2)$. The greater momentum of the REF atomizer's air assist stream 


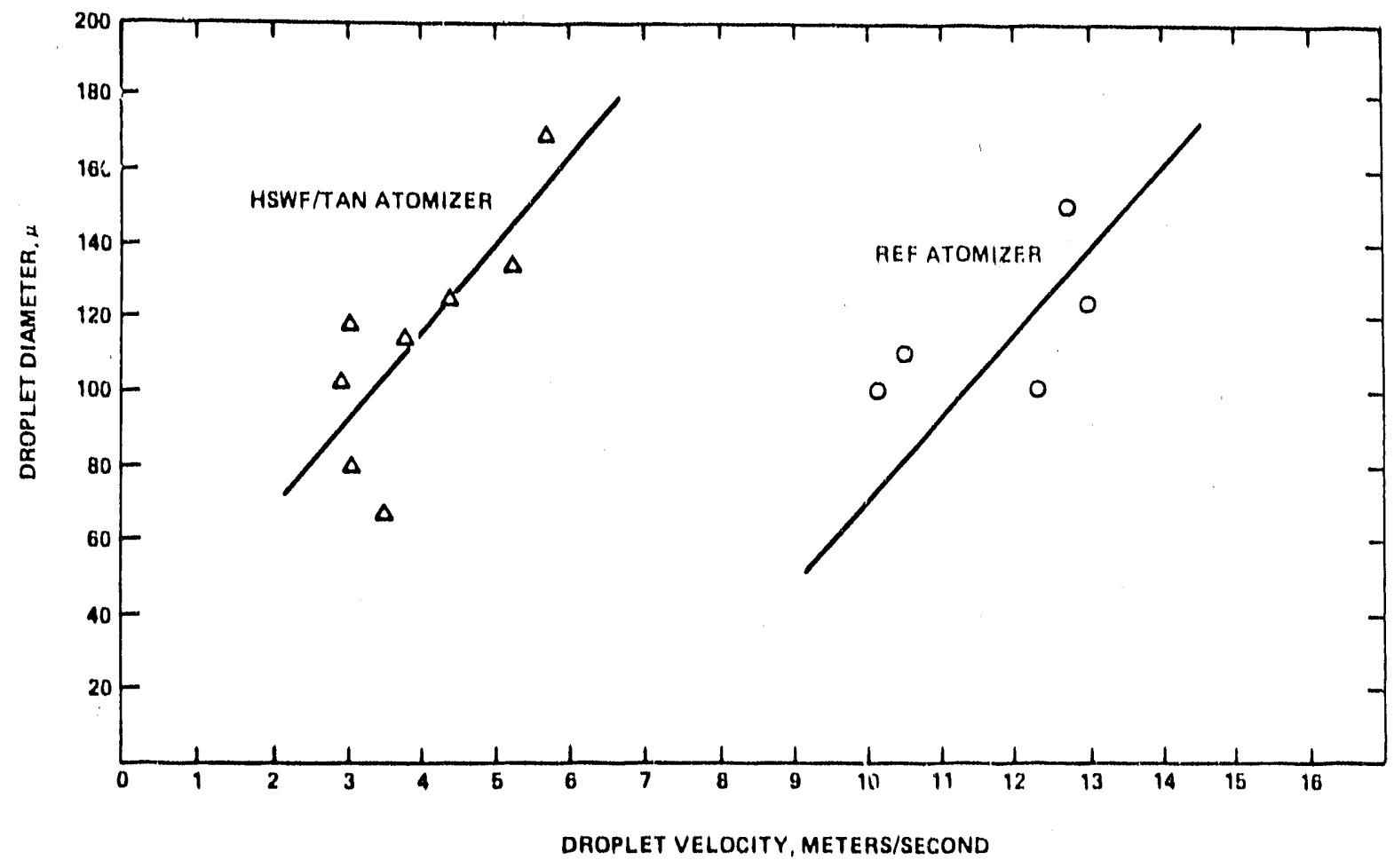

FIGURE 10: DROPLET VELOCITY VERSUS DROPLET DIAMETER AT 100\% LOAD 
as compared with that of the HSWF/TAN atomizers may increase the total momentum (mass, velocity product) of the partially atomized fuel stream issuing from the REF atomizer. This may increase measured droplet velocities downstream of the atomizer exit.

It should also be noted that droplet trajectories for the HSWF, TAN, and REF atomizers tended to predictably follow the streamlines of a freely expanding jet.

Ballistics data for the REF/REG atomizer is unavailable due to an instrumentation failure, however, it is likely that droplet velocities and trajectories are similar to those observed for the HSWF and TAN atomizers, as the atomizer designs are generically similar and the operating $A / F$ ratios are in a similar range. 


\section{COMPARATIVE COMBUSTION PERFORMANCE OF EACH GENERIC BURNER SYSTEM}

The overall objective of this portion of the project was to measure the combustion characteristics of each burner type, so that the potential commerciality of each generic burner design for retrofit to oil-designed units could be assessed. Preliminary Performance Objectives (PPO) previously established to provide performance targets , ur each burner vendor were used as guidelines.

Each burner was initially evaluated through a series of preliminary tests to identify potential performance problems which could be corrected prior to detailed performance characterization. The preliminary tests included cold flow atomization testing, combination shakedown/optimization testing and an abbreviated performance characterization. Following the preliminary tests, each burner manufacturer was provided the opportunity to modify equipment. The burners then underwent more detailed combustion performance testing.

All burners were evaluated with the same reference fuel in the same test furnace. The Industrial Scale Burner Test Facility (ISBTF) employed throughout this testing simulates a front wall, horizontal fired industrial type boiler environment. Figure 11 outlines the physical appearance of this facilicy. The combustion chamber of the facility is surrounded by an atmospheric pressure water jacket. Chamber wall temperatures can be adjusted by the addition or removal of refractory panels to allow simulation of specific heat release profiles and furnace temperatures. 


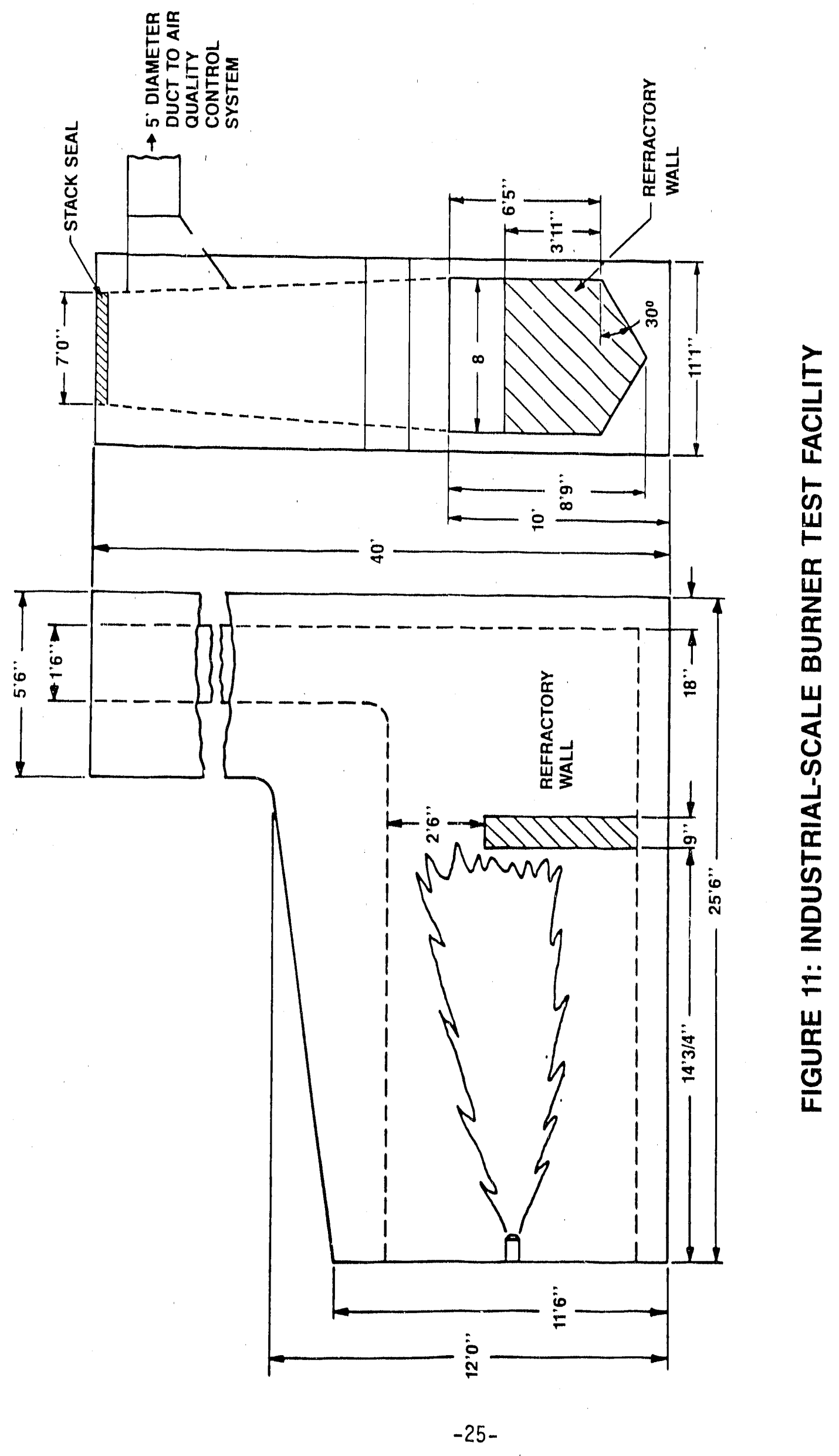


For the combustion testing, a volumetric heat release rate of approximately $30,000 \mathrm{Btu} / \mathrm{hr}^{-\mathrm{ft}^{3}}$ was chosen as being representative of the majority of the 0il-fired boilers and process heaters which have the greatest potential for CWF retrofit. To obtain this heat release rate, a refractory brick wall was constructed 14 feet downstream of the furnace front wall. A layer of blanket refractory insulation was added to the ISBTF walls and ceiling to obtain furnace outlet temperatures on the order of 2400 to $2500^{\circ} \mathrm{F}$. Fue 1 particle residence times are estimated to be on the order of 1.7 seconds, utilizing a plug flow approximation for bulk gas velocity.

Flue gases are channeled from the ISBTF to a venturi rod scrubber. This scrubber is used during all combustion testing to meet local and federal air quality standards for $\mathrm{SO}_{2}$ and partizulate emissions.

The ISBTF is capable of a maximum firing rate of $72 \times 10^{6} \mathrm{Btu} / \mathrm{hr}$ on typical oils and $50 \times 10^{6} \mathrm{Btu} / \mathrm{hr}$ on coals or coal-based fuels. Support equipment consisting of solid fuel pulverization and storage facilities and slurry fuel handling facilities provide capabilities for a wide range of fuel types and their associated firing equipment.

Facility instrumentation employed during the subject project included:

- Flue gas constituent monitors for $\mathrm{CO}_{2}, \mathrm{CO}, \mathrm{O}_{2}, \mathrm{NO}_{x}$, and $\mathrm{SO}_{2}$

- Flue gas particulate collection equipment (EPA Method 5)

- Heat Flux instrumentation

- Suction pyrometers for gas temperature measurements. 
A primary performance criteria for most potential CWF burner users will be carbon conversion efficiency (CCE), since CCE is influential in determining the economics of CWF conversion. The PPO target was to achieve greater than $98 \%$ CCE at $25 \times 10^{6} \mathrm{Btu} / \mathrm{hr}$ ( $100 \%$ of ful1 10ad) heat input. The performance of each burner with respect to CCE was determined principally by analysis of flue gas constituents $\mathrm{CO}_{2}$, $\mathrm{CO}_{2}$, and $\left.\mathrm{CO}\right)$. CCE's determined by flue gas analysis were also confirmed at selected test points by analysis of isokineticallyobtained fly ash samples for carbon content.

The HSWF burner was capable of achieving CCE levels greater than $97 \%$ at $100 \% 10$ ad, while the TAN burner was capable of CCE's greater than $99 \%$ when operating at $100 \%$ load conditions. The HSWF burner's performance with respect to CCE nearly met the PPO target, while the TAN burners performance exceeded PPO expectations. The REF/REG burners, using the best atomizer supplied by the burner vendor, was capable of CCE's in excess of the PPO target level of 98\%, contrasting with the REF burner which achieved CCE's on the order of $86 \%$ at 100\% load firing conditions. CCE for the REF burner improved at reduced firing rates (to the $95 \%$ level). However, it appeared that the REF burner would benefit from additional development in order to improve CCE.

A11 four burners were sensitive to excess air level. Increasing excess combustion air tended to improve CCE in all cases. Figure 12 summarizes the measured effect of excess air on CCE. Note that a11 tested burners can operate within the PPO target of $40 \%$ excess air.

Several tests were conducted in order to quantify the effect that combustion air preheat has on burner operation. The PPO target for preheat called for combustion air temperature not to exceed $500^{\circ} \mathrm{F}$, derived primarily from conversion economics considerations. (Economics of conversion to CWF improve when burners require minimal levels of combustion air preheat.) 


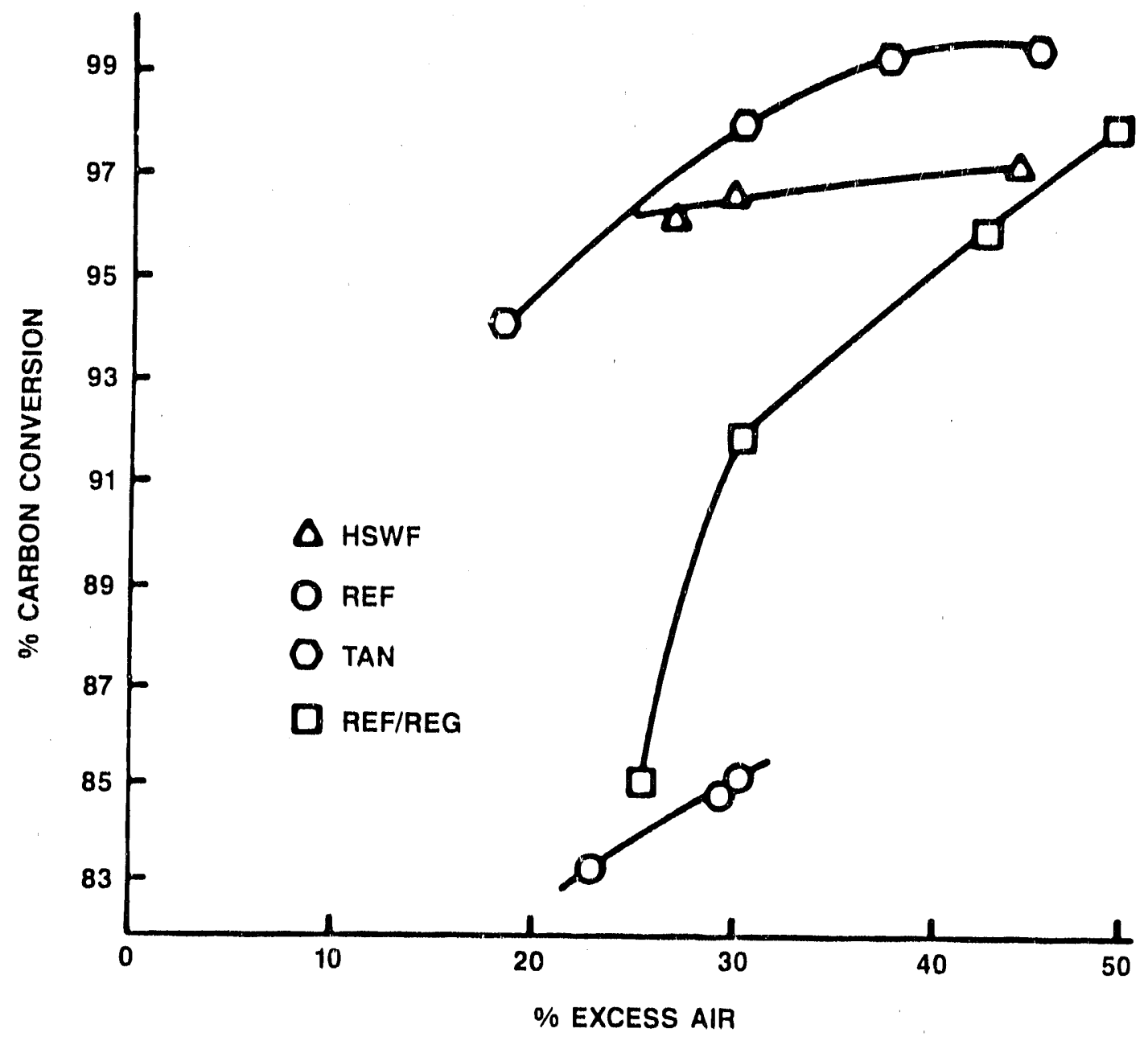

FIGURE 12: COMPARATIVE COMBUSTION RESULTS 
While combustion air preheat can influence a number of burner performance parameters, it's influence can be most readily seen by observilig relative flame stability. Air preheat affects flame stability through its impact on fuel ignition properties. With this in mind, each burner's flame stabllity was assessed at various combustion air temperatures.

The HSWF burner operated with acceptable flame stability at combustion air temperatures as low as $300^{\circ} \mathrm{F}$. It should be noted that CCE degraded by $0.4 \%$ when the HSWF burner was operated with combustion air temperatures below $500^{\circ} \mathrm{F}$.

The TAN burner was capable of operation at combustion air temperatures down to $250^{\circ} \mathrm{F}$. Data from this testing indicated that CCE was not affected by combustion air temperature for the TAN burner over a temperature range of $250^{\circ} \mathrm{F}-600^{\circ} \mathrm{F}$.

The REF burner and REF/REG burners operated stably at the combustion air temperature of $500^{\circ} \mathrm{F}$, but the REF burner's flame stability deteriorated at temperatures below $500^{\circ} \mathrm{F}$. The REF/REG burner vendor did not recommend burner operation with combustion air temperature below $500^{\circ} \mathrm{F}$, due to expected flame stabllity problems.

The PPO target for burner turndown was for each burner to achieve a firing rate turndown ratio in excess of 4 to 1 without any support fuel or supplementary ignition sources. The test burners' turndown performance was found to vary widely. For example, the REF burner was capable of achieving 4 to 1 turndown with acceptable flame stability, while the HSWF burner and TAN burner achieved turndowns of 2.5 to 1 and 2 to 1 , respectively. The REF/REG burner's turndown was limited to 1.5 to 1 at best. 
The PPO target for burner ignition energy was that each burner should achieve stable operation after providing ignition support energy equivalent to $20 \%$ of full load heat input $\left(5 \times 10^{6} \mathrm{Btu} / \mathrm{hr}\right)$ for a period of time not to exceed 30 minutes in a cold boiler. It should be noted that all burners in the test program were successful in meeting this ignition energy guideline.

Combustion air windbox pressure requirements were noted for each generic burner. It is desirable from an overall plant efficiency standpoint to minimize burner windbox pressure. The PPO target was for each burner to not exceed 16 inches water column windhox pressure. Relative ranking of the burners with respect to operating windbox pressures were 1) TAN (5.1" W.C. C 44\% excess air), 2) HSWF (9.8" W.C. O $44 \%$ excess air), 3) REF (17" W.C. (30\% excess air) and 4) REF/REG (19.5" W.C. $48 \%$ excess air).

Flame scanners are an integral component in burner management and safety systems. Tests were conducted to quantify relative compatibility of each burner's flame scanning system to CWF firing. Two generic flame detection systems were employed by the burner vendors participating in these tests. The HSWF and TAN burners used a visible light intensity/frequency monitor, while the REF and REF/REG burners used infrared detectors. Based on this test program, it appears that both visible light intensity/frequency monitors and infrared scanners can be successfully employed with CWF firing systems.

A factor which may limit the potential for CWF burner retrofit is that additional burner/boiler maintenance may be required as compared with existing oil fired burners. The reason for this concern derives from the fact that the pulverized coal in CWF's contains varying quantities of mineral matter in the form of ash. This ash is potentially erosive and can form deposits on burner/boiler surfaces. Two PPO targets were established with 
respect to the above: 1) that no excessive coking (deposition) occurred on burner surfaces during eight hours of steady burner operation and 2) that no atomizer pluggage or erosion occurred after eight hours of steady burner operation.

No burner coking or deposition was observed with efther the HSWF or TAN burners. Some limited deposition was observed with both the REF and REF/REG burners. However, the deposition observed did not impede burner operation.

The HSWF, TAN, and REF atomizers did not expertence any atomizer pluggage or erosion over eight hours of burner operation. These atomizers were fabricated of erosion resistant materials specifically for application to CWF. The REF/REG burner's atomizers tended to wear after only three hours of operation. However, the atomizers were fabricated of carbon steel, which is not particularly erosion resistant. Had the REF/REG atomizers been fabricated with erosion resistant materials, then REF/REG atomizer life would have improved dramaticaliy.

The final PPO burner performance target addressed atomizer energy consumption requirements. All burners in the test program employed air-assisted atomizers; compressed air is used to provide fuel atomization energy. Since the amount of compressed air required for atomization effects overall plant efficiency, a PPO target $1 \mathrm{imit}$ was set for atomizer air consumption. Atomizer air consumption is normally expressed as an atomizing air to fuel (A/F) mass flow ratio. The PPO target was set at the $A / F$ ratio of 0.25 . This ratio was consistent with air consumption guidelines set by EPRI (Ref 5 ) for CWF atomization.

$A / F$ ratio has a first order effect on atomization quality; atomization quality improves with increases in $A / F$ ratio. This phenomena was observed for a11 burners in the test program. 
Optimum burner performance was achteved at the following $A / F$ rattos:

Burner Type

HSWF
REF
TAN
REF/REG

\section{A/F Rat to Range}
$0.19-0.22$
$0.53-0.55$
$0.19-0.22$
$0.19-0.29$

It is clear in reviewing the above that the HSWF and TAN atomizers met the PPO guideline, and the REF/REG atomizer for the most part operated within an acceptable $A / F$ ratto range. The REF atomizer only operated at $A / F$ ratio's which exceeded the PPO 1 imitation.

In summary, all burners in the program were capable of firing the reference CWF. However, each burner demonstrated unique performance characteristics. No tested burner concept could be deemed wholly inadequate for CWF service. The HSWF and TAN designs appear suitable for imnediate commerctal CWF retrofit application. The REF and REF/REG burners demonstrated promising performance, but would benefit from further development. It should be noted that the REF and REF/REG burner manufacturers had no significant experience with CWF firing prior to this test program. 


\section{Mult L le CWF Formulation Test Program}

VII. BURNER SELECTION FOR $50 \times 10^{6}$ BTU/HR

Having quantifted the relative performance oi each $25 \times 10^{6} \mathrm{Btu} / \mathrm{hr}$ genertc burner design, the project's focus centered on selecting a generlc burner design for applitiation to the multiple CWF formulation test program to follow. These tests wele to be conducted at a $100 \%$ load heat. input of $50 \times 10^{6} \mathrm{Btu} / \mathrm{hr}$. Therefore, the burner design selected would require scaling to a $50 \times 10^{6} \mathrm{Btu} / \mathrm{hr}$ heat input capacity. Specific burner selection criterta included:

1) Burner design sultability to a wide range of botler retroftt applications.

2) Burner design compatiblitty with PPO levels of performance

3) Impact of burner delivery on project schedule

4) Impact of burner selection on project budget.

Due mostly to consideration of the first criterton, the High-Swtrl Wall Fired (HSWF) Burner was chosen for application to the multiple CWF formulation test program. The HSWF genertc design is sultable for use in a variety of CWF retroftt situations. It was determined that a $50 \times 10^{6} \mathrm{Btu} / \mathrm{hr}$ HSWF burner could be integrated into the project with positive impacts of both project budget and schedule. In addition, the HSWF burner design operated within most PPO target performance levels.

The HSWF burner manufacturer fabricated a $50 \times 10^{6}$ Btu/hr capactty burner with improvements to the design with respect to minimizing required burner windbox pressure. Specifically, the tertiary atr swirler was eliminated from the design, which effectively allowed the burner to operate at windbox pressures below those previously observed (1.e., less than 9.8" W.C. O 44\% excess air). A schematic. of the $50 \times 10^{6}$ Btu/hr HSWF burner is shown in Figure 13. 


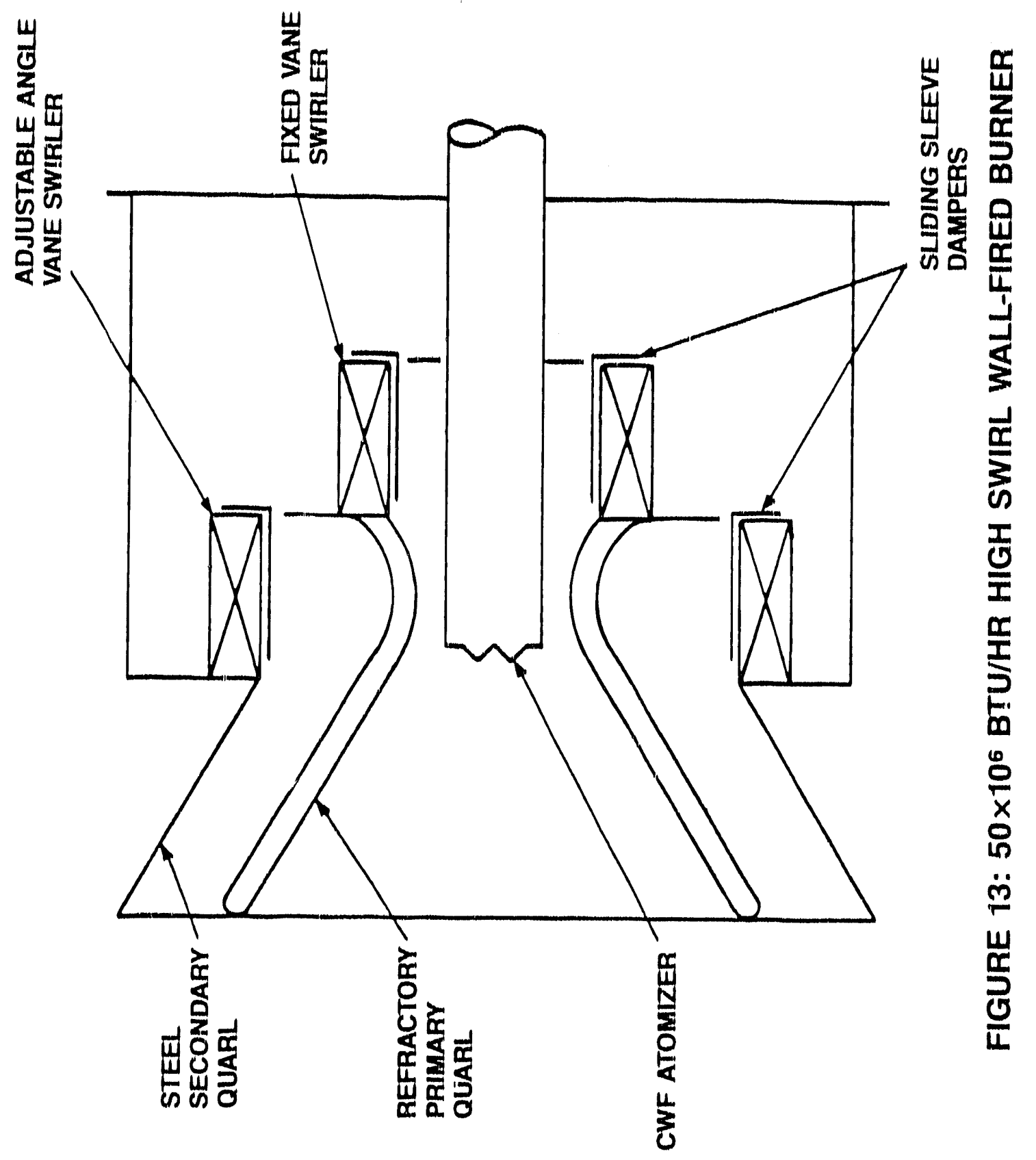


The overall objective of this portion of the project was to characterlze and compare the performance of ftve different coal-water fuel (CWF) formulations which have commercial potential for replacing conventional premium fuels in industrial and utflity botlers. Direct comparisons between each fuel's relative performance could be drawn since the testing environment (i.e., burner and test furnace) for each fuel was held constant. The information gathered as a result of the project can be used by potential users to assess the technical feastbility of uttlizing CWFs sourced from several commerctal supplters who employ differing formulation approaches.

A detalled laboratory analysts program was inttially carried out to charactertze the ftve chosen CWFs in terms of thetr chemical and rheological properties. All CWFs chosen were formulated with high volatile A bituminous coals from mines in the eastern U.S.

Identifying codes, summarized below, were assigned to the fuels in the program. These codes identify a specific CWF's coal type, ash level, and vendor. The vendors are identifted by code letter to preserve their anonymity:

\begin{tabular}{clcc} 
Euel Identifier & \multicolumn{1}{c}{ Coal Type } & \% Ash (Dry Basts) Vendor Code \\
SD63C & Splash Dam & 6.3 & $\mathrm{C}$ \\
SD52A & Splash Dam & 5.2 & $\mathrm{~A}$ \\
CG53C & Cedar Grove & 5.3 & $\mathrm{C}$ \\
UF62C & Upper Freeport & 6.2 & $\mathrm{C}$ \\
SD71F & Splash Dam & 7.1 & $\mathrm{~F}$
\end{tabular}


Laboratory evaluation of these fuels included the following characterization tests:

1) Solids content

2) Proximate analysis

3) Uitimate analysis

4) Higher heating value

5) Ash Fusibility

6) Ash Composition

7) Screen Size Analysis

8) Low shear viscosity (Haake viscometer) (Ambient Temperature Fuel)

9) High shear viscosity (Burell viscometer) (Ambient Temperature and Heated Fuel)

Note that no attempt was made to characterize any commercial additives which typically comprise about $1 \%$ by weight of most CWF mixtures in order to prevent settling or enhance rheological properties. These additive packages are considered proprietary by the respective fuel manufacturers.

In addition, it should te noted that all testing in this program was conducted on fuels in their as-delivered states (1.e., no dilution).

Table 3 presents a tabulated summary of the major results from the laboratory testing phase. The discussion which follows highlights key fuel characteristics which can impact a fuel's ablitity to atomize and combust efficientiy. 


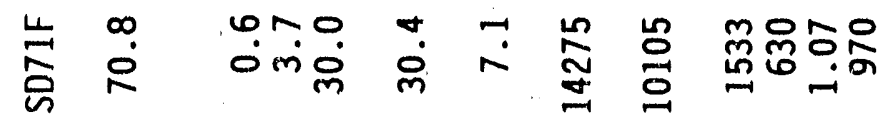

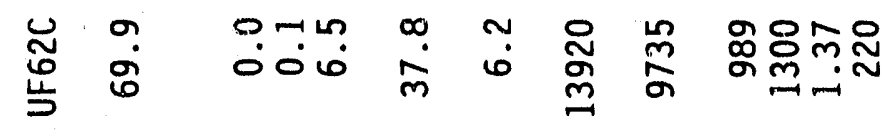

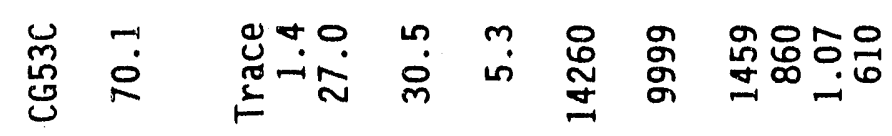

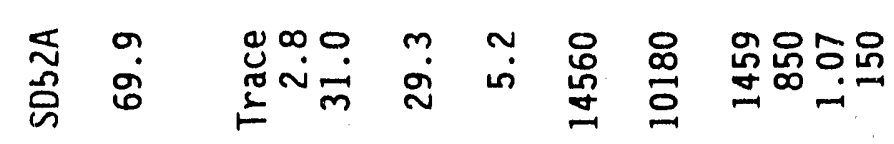

曾安

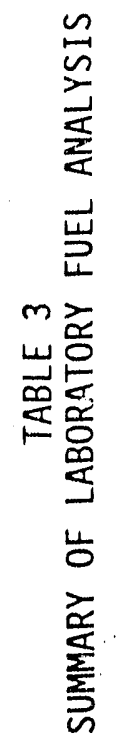

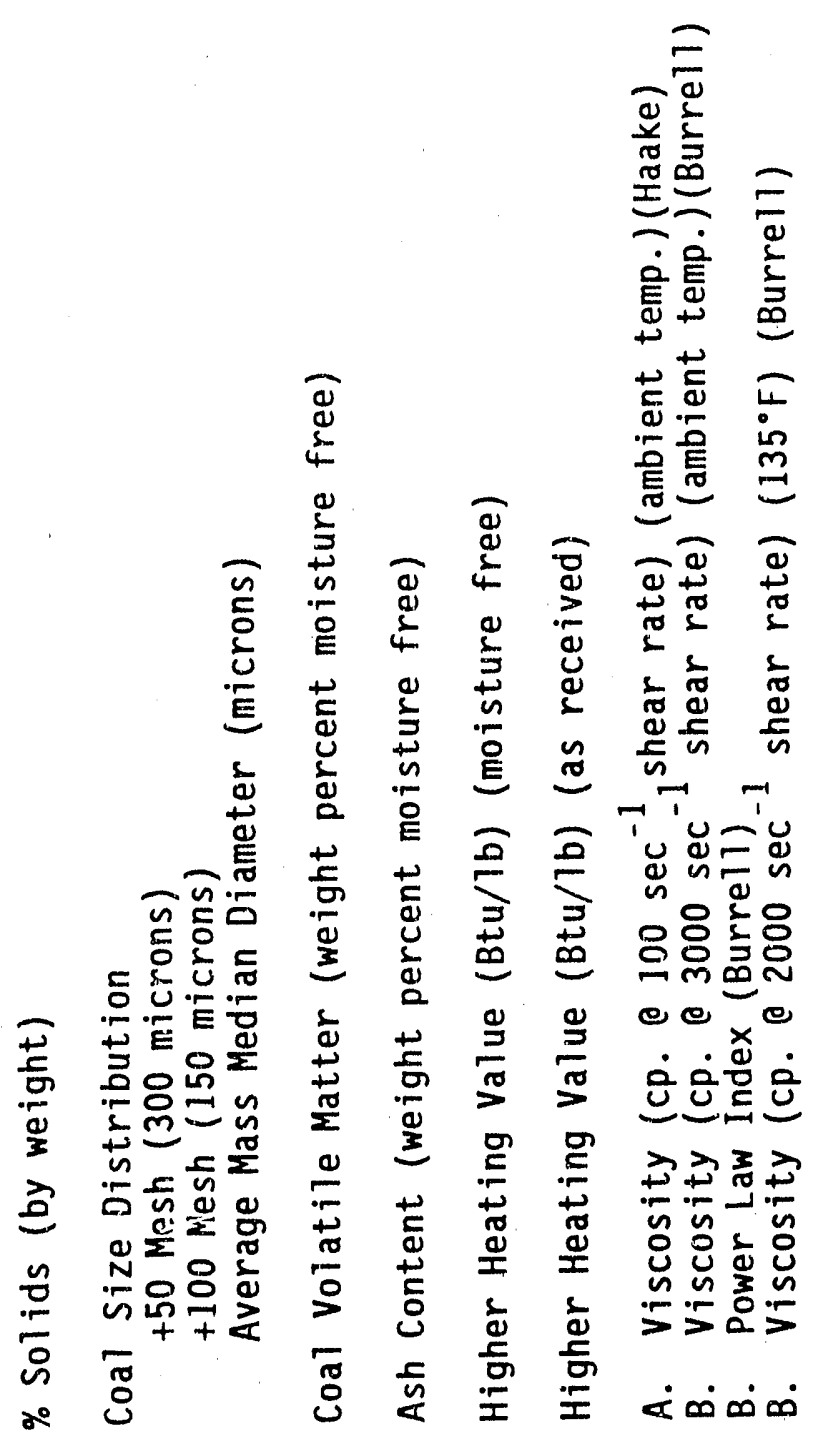


Coal particle size distribution and coal particle top size can impact on combustion performance in conventional pulverized coal firing (4). Finer coal grinds enhance combustion as they promote fuel/air mixing through an increase in fuel surface area. Assuming the same analysis held true for CWF firing, (disregarding atomization/agglomeration mechanisms for the moment) one could presume that finer grind CWF's would combust more readily and completely than coarser grind fuels.

Figure 14 presents a comparison of the coal particle size distribution (Rosin-Rammler Analysis) for the five CWF fuels tested. The five fuels fall into two major categories as delineated by their respective coal particle size distributions. Fuels UF62C and SD63C can be considered microfine CWF's, with coal particle mass median diameters approximately equal to 6.5 microns. Fuels SD52A, SD71F, and CG53C are considered standard grind CWF's with coal particle MMD's ranging from 27 to 31 microns. Assuming the base coals were fired in a dry, pulverized state (again ignoring any agglomeration phenomena), the microfine coals would probably fire at higher levels of carbon conversion efficiency than would the more conventional grind coals, all other factors being equal.

The value of volatile matter content is used as an indication of coal classification and ignitability, and, in general, high volatile matter content (approx. $30 \%$ or above) is desirable in coal firing as it enhances fuel ignition and flame stability. Figure 15 presents a comparison of the volatile matter content for the five fuels. As can be seen, all of the fuels have essentially identical volatile matter content, with the exception of UF62C which has a somewhat higher value. Thus, it can be expected that all of the base coals would have good ignition characteristics and will maintain good flame stability if fired as dry pulverized fuels. 


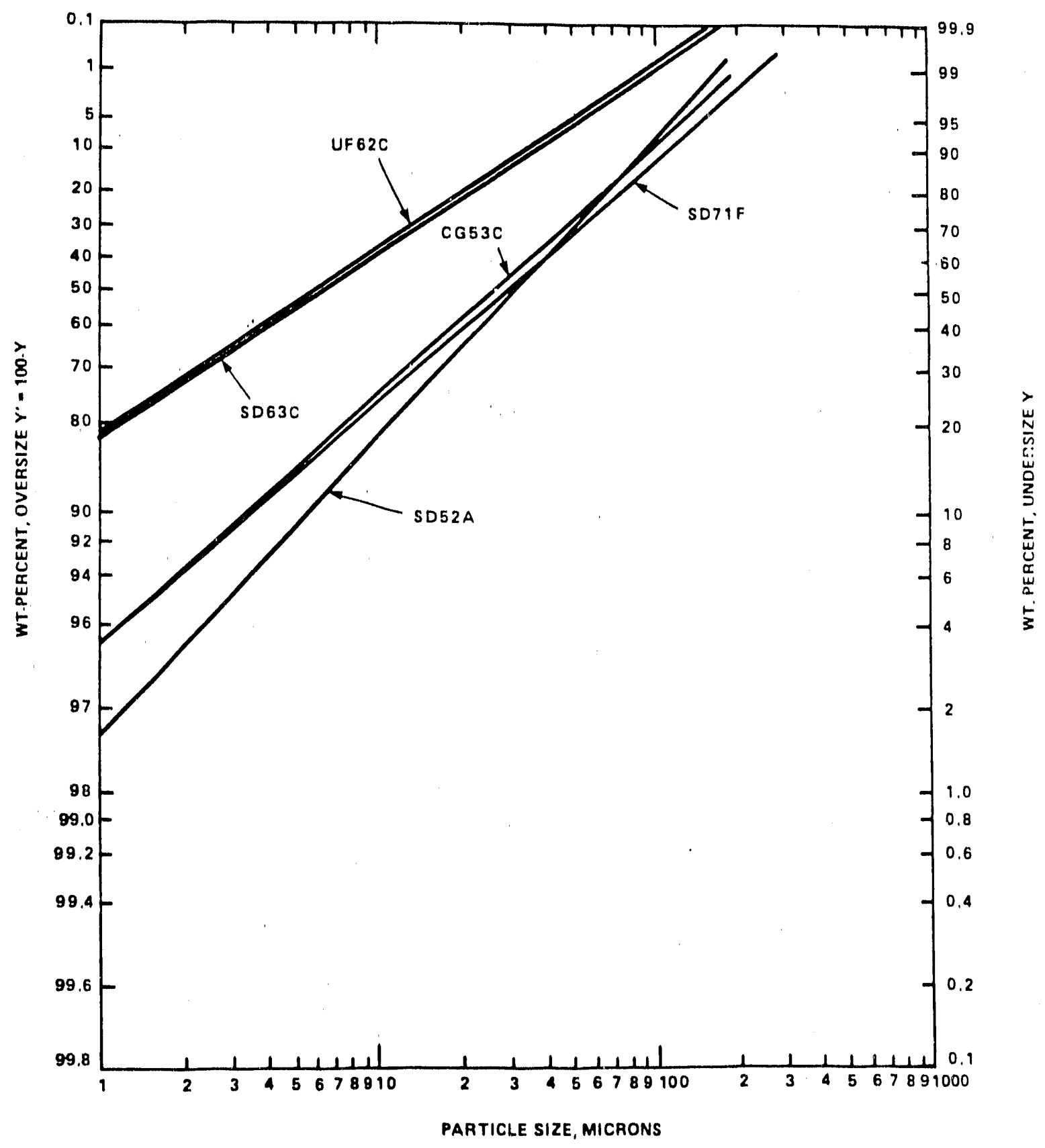

FIGURE 14: COMPARISON OF THE COAL PARTICLE SIZE DISTRIBUTION FOR THE FIVE CWF'S TESTED 


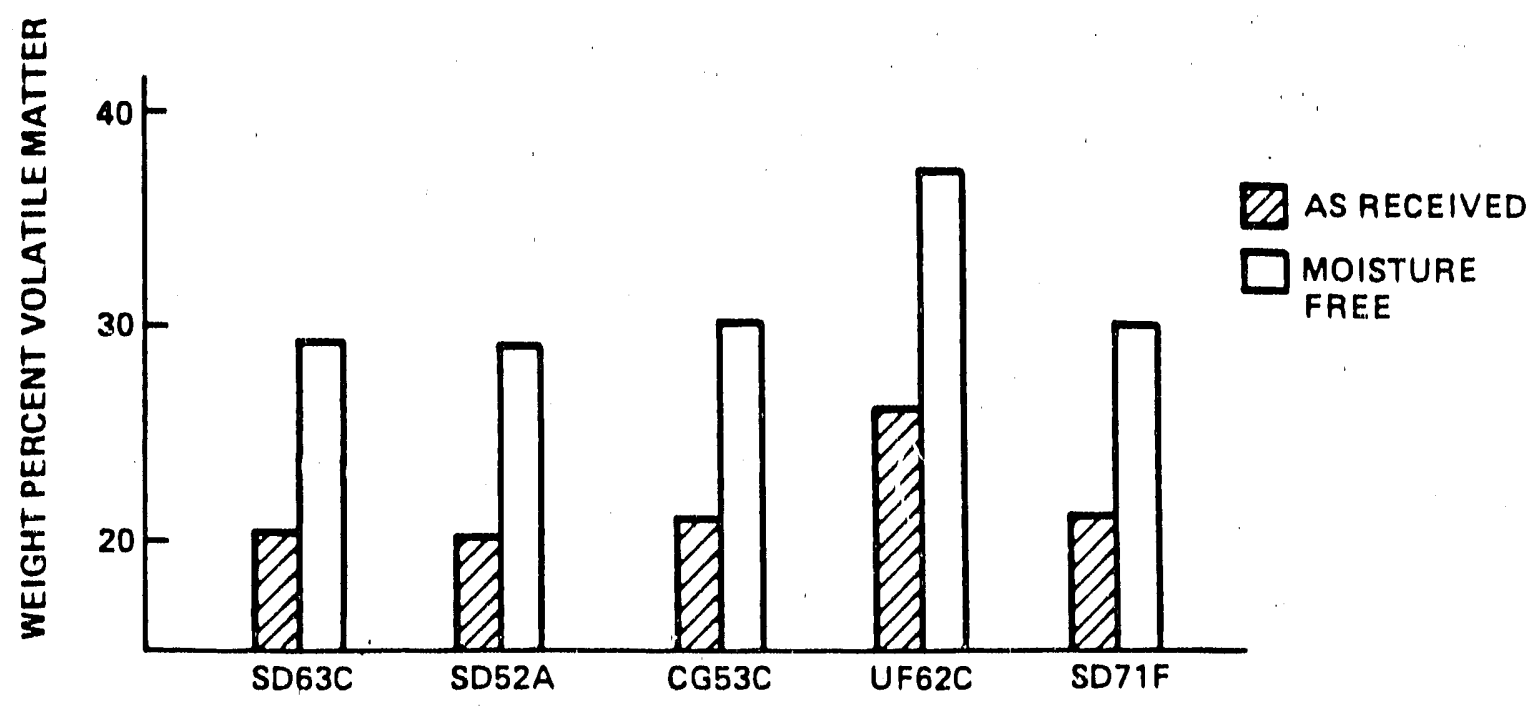

FIGURE 15: COMPARISON OF VOLATILE MATTER

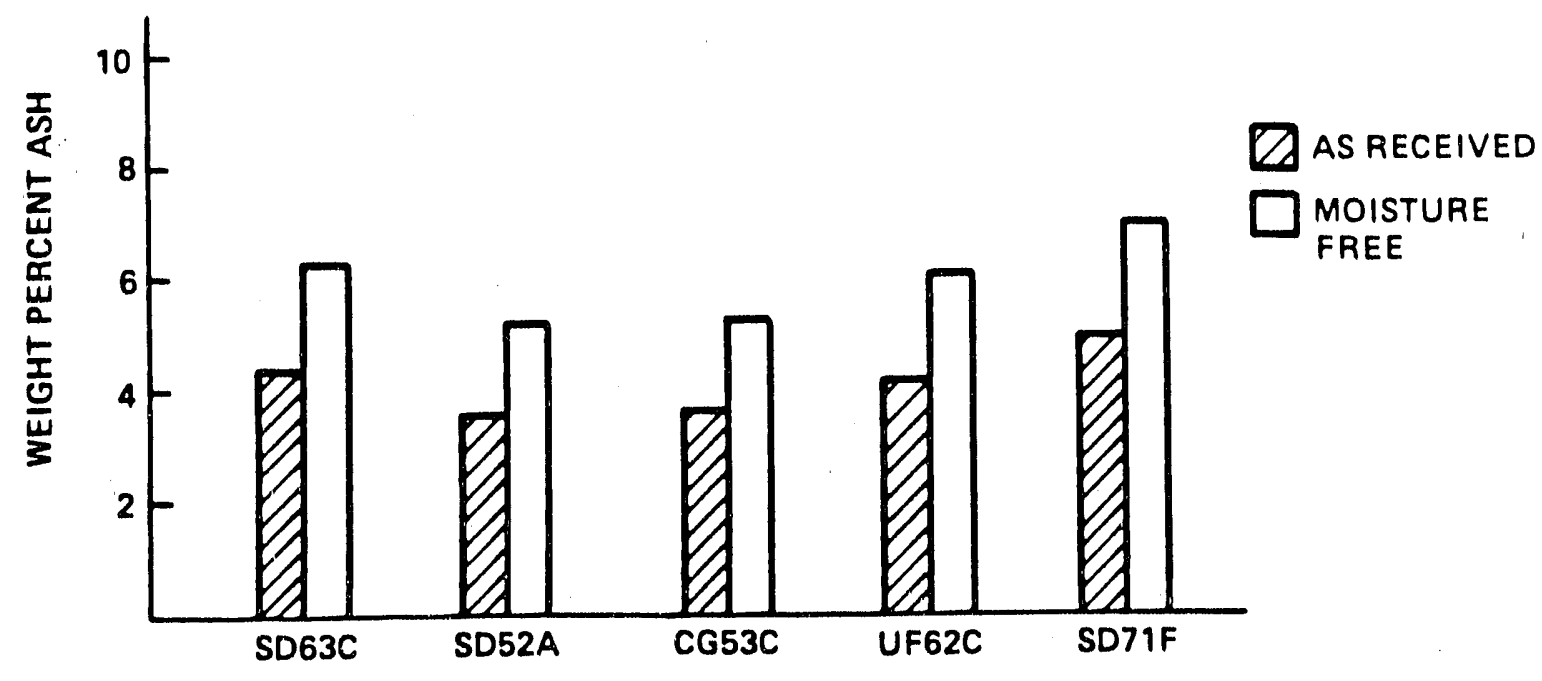

FIGURE 16: COMPARISON OF ASH CONTENT 
Ash composition and ash content are important variables in any CWF formulation, since boller convection tube erosion is directly related to these factors. Convective tube erosion resulting from flyash generated during combustion must be a major consideration when retrofitting bollers designed for low ash level fuels to higher ash level CWF firing. Several investigators $(6,7)$ have indicated that the potential for boiler pressure part erosion could be a significant load limiting factor, and would adversely affect the economics of CWF conversion in some cases.

Most commercial CWF vendors beneficiate the base coals utilized in CWF's in order to minimize the impact of increased fuel ash content on both tube erosion and boiler flyash collection systems. Thus, all parent coals in this study were beneficiated to some degree prior to CWF production. Figure 16 shows a comparison of the ash levels for the five fuels on an as-received and moisture-free basis. As can be seen in Figure 16, ash levels ranged from 5.2 to $7.1 \%$ by weight on a dry basis. A study of the impact of CWF ash composition and ash level on boiler tube erosion was beyond this scope of work. However, studies have been reported el sewhere $(7,8)$ which characterize the effects of CWF ash on erosion.

Viscosity is a measure of a fluid's resistance to flow. Fluids are typically categorized as being either Newtonian or non-Newtonian in nature. Newtonian fluids are characterized by viscosities that are independent of shear rate while non-Newtonian fluids exhibit viscosities that are shear dependent. Most conventional petroleum based boiler fuels are Newtonian fluids. Consequently, their transport flow characteristics, which relate to viscosity under low shear conditions, and, to a certain extent, their atomization characteristics, which can be related to viscosity at much higher shear rates, can be analytically predicted with shear viscosity 
information derived at a single shear rate. This is not the case with CWF's, since most CWF's exhibit non-Newtonian behavior, as did the five fuels studied in this program. This fact complicates the analytical prediction of viscosity related CWF characteristics, such as piping pressure losses and atomization quality.

In order to characterize the complex non-Newtonian rheology of the five CWF's, a series of parametric viscosity measurements was made. These measurements were conducted over a range of shear rates from $100 \mathrm{sec}^{-1}$ to $8000 \mathrm{sec}^{-1}$. This range of shear rates may be considered fairly representative of the flow regimes a CWF may be exposed to when being handled (pumped) from a storage tank to a botler and then subsequently atomized within the burner's atomizer. A sensitivity study was also conducted in order to define the impact of temperature on CWF rheology. Viscosity measurements were made at a constant shear rate $\left(2000 \mathrm{sec}^{-1}\right)$ over a range of CWF temperatures from $75^{\circ} \mathrm{F}$ to $160^{\circ} \mathrm{F}$.

The low shear $\left(100 \mathrm{sec}^{-1}\right)$ viscosity data, as measured by a Haake Rotovisco Viscometer, were summarized in Table 3. Figure 17 presents the high shear viscosity data obtained with a Burrell high shear viscometer. As can be seen, the fuels are clearly nonNewtonian with each fuel being dilatent in nature. Of the five fuels, fuels SD63C and UF62C exhibited the highest degree of dilatency with power law indices of 1.4 and 1.37. The other three fuels showed identical degrees of dilatency, each having a power law index of 1.07. Note that fuel UF62C had the highest range of high shear viscosity (from 1075 to 1475 centipotse) and that fuel SD7.1F had the lowest range (between 620 and 700 centipoise). 


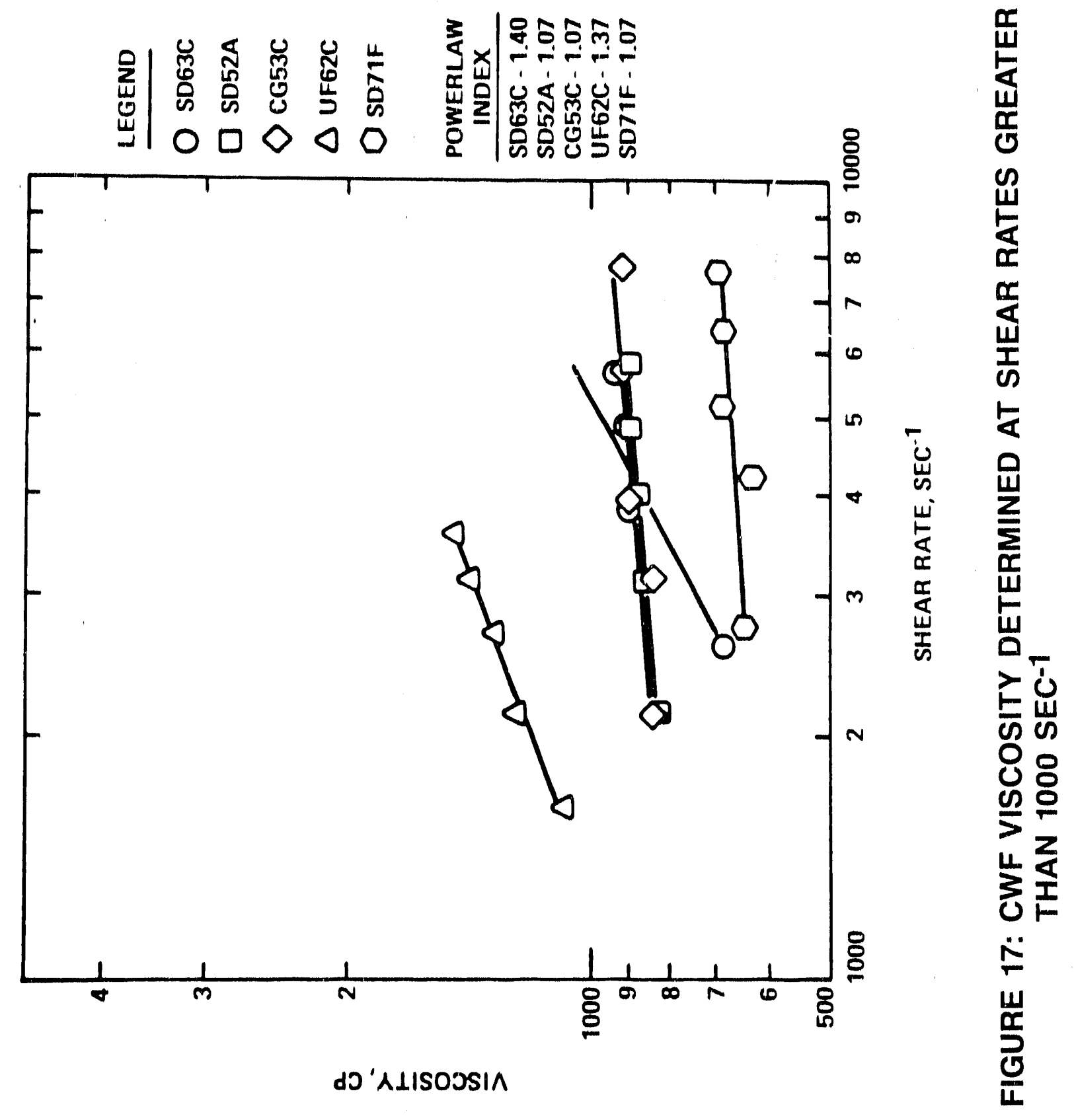


Viscosity has been shown (9) to have a first order effect on the atomization quality of Newtonian fluids. CWF atomizer's typically operate at high shear rates $\left(>5000 \mathrm{sec}^{-1}\right)$. Assuming that high shear viscosity also has a first order effect on CWF atomization and disregarding any other influences, one could make the prediction that fuel SD71F would atomize more finely and combust more readily than would fuel UF62C.

Figure 18 presents a comparison of high shear viscosity values as a function of temperature, ranging from 75 to $160^{\circ} \mathrm{F}$, for the five fuels. These measurements were performed by the Adelphi Center for Energy Studies with the fuel samples sent directly from each vendor. As shown, all of the fuels, with the exception of UF62C, exhibited viscosities that were highly dependent on fuel temperature, with viscosity generally decreasing as temperature was increased. The sample of fuel UF62C analyzed by Adelphi underwent settling and it is likely that the shear viscosity data obtained are not representative.

\section{ATOMIZATION CHARACTERIZATION}

Most CWF investigations to date have identified the fuel atomization process as critical to efficient combustion. The situation is analogous to firing conventional liquid fuels. That is, fine fuel sprays enhance ignition and carbon conversion efficiency as compared with fuel sprays having a relatively significant population of large diameter droplets.

A parametric study was conducted in order to quantify the effect that various CWF formulations would have on atomization quality. This testing was carried out on the five CWF's in thi program using Combustion Engineering's Atomizer Test Facility (ATF) described in previous sections of this report. Performance comparisons can be drawn between each fuel as all CWF's were atomized under identical conditions using the same $50 \times 10^{6} \mathrm{Btu} / \mathrm{hr}, \mathrm{Y}$-jet CWF nozzle. 


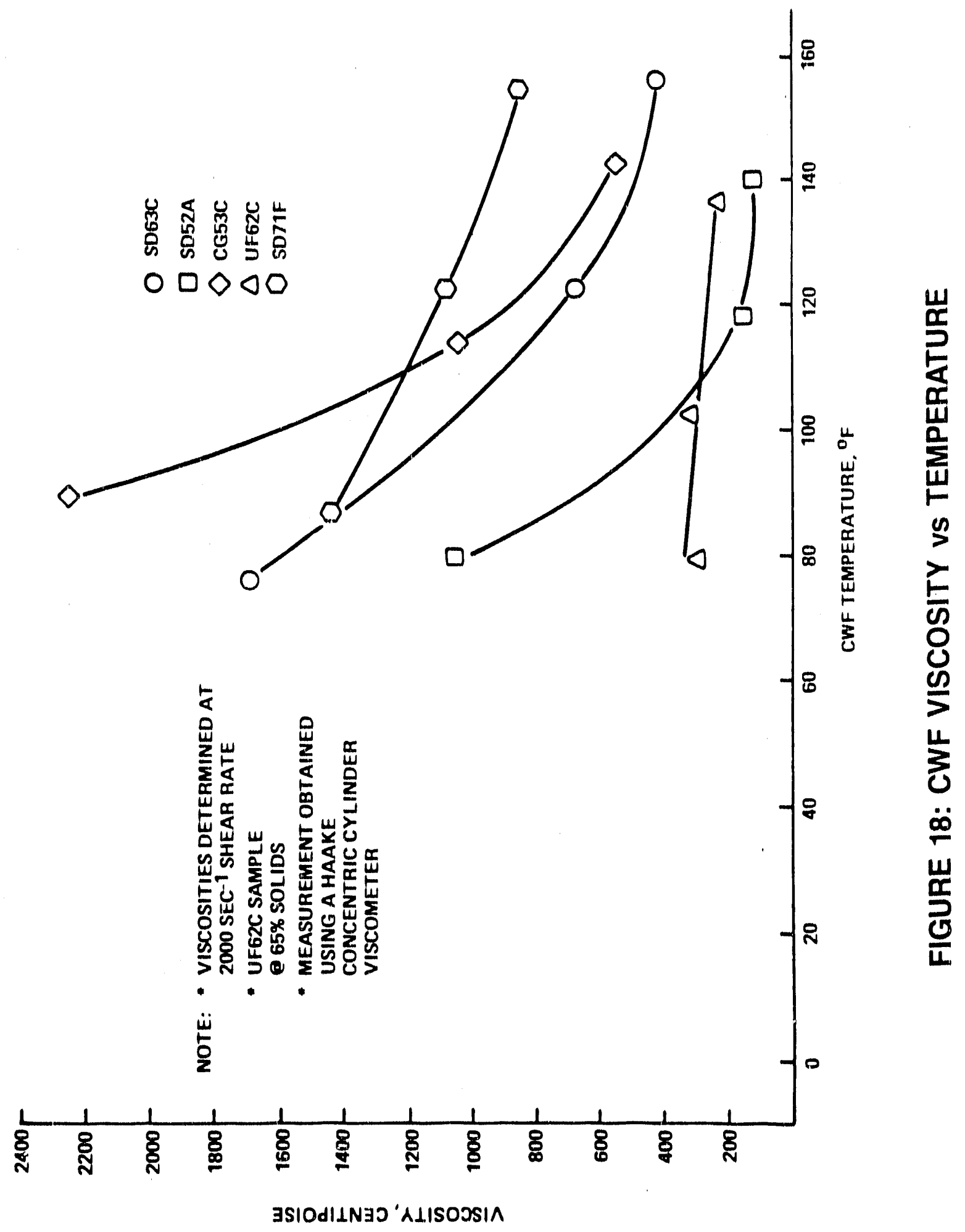


In general, to reach any valld conclusions on atomlzation performance, a set of performance criterta for CWF must be established by which a comparison can be made with experimental data. Spectfically, performance objectives in terms of droplet size distribution and atomizer energy consumption need to be developed. During the burner evaluation phase of this program, Combustion Engineering estabilished a number of Preliminary Performance objectives (PPO's) in order for the burner manufacturers to have established design targets.

In the spectfic area of atomizer design, it was deemed desirable to have: 1) An atomized spray droplet mass medtan diameter (MMD) of less than 200 microns at $100 \% 10$ ad, 2) less than $1 \%$ by weight of total spray droplets exceeding 300 microns in dtameter and 3) An atomizer assist flutd consumption ratio (A/F) of less than $0.25 \mathrm{lb}$ atr/lb fuel at $100 \%$ of ful1 load firing rate.

These PPO's were met or exceeded by the HSWF burner's atomizer on a baseline CWF. The atomizer was capable of achleving, on average, a spray droplet mass median diameter of less than 70 microns while meeting the droplet top size and energy consumption criterta outlined above.

The primary focus of this test phase was to determine, for each fuel tested, the effect of $A / F$ ratio on spray droplet MMD, size distribution and topsize. The atomizer test matrix was designed to evaluate atomizer performance over a range of operating conditions with tests conducted at three fuel rates corresponding to $100 \%, 50 \%$, and $33 \%$ 10ad (with 100\% load equivalent to a burner firing rate of $50 \times 10^{6} \mathrm{Btu} / \mathrm{hr}$ ). Compressed air was used as the atomizing media and the $A / F$ ratio was systematically varied for each of the three loads. 
A11 spray droplet size measurements were made approximately 150 nozzle diameters downstream of the nozzle extt. Testing at this location ensured that the fuel atomlzation process was complete and only spherical droplets were present in the measurement volume. Testing of each fuel in the ATF was conducted pritor to each fue 1 being fired in the combustion test phase of the project. Each fuel was deltvered in a conventional, pressurized tanker, and 500 gallon samples for ATF testing were drawn from a well mixed storage tank.

Figure 19 presents a compartson of the spray mass median dtameter as a function of $A / F$ ratio at $100 \%$ load for the five CWF's. Note that, with the exception of fue1 UF62C ( 44 micron MMD), the atomization quality of all the fuels was simtlar (60 to $70 \mathrm{micron} M M D)$ within the atomizer's recommended $A / F$ operating range of 0.19 to 0.21 .

In Figure 20 the entire drop size distribution for each of the five fuels is presented. Note that the droplet stze data are dertved from the Malvern instrument's Rosin-Rammler analysis routine. Based on this information, each fuel generated fewer than one percent by weight of droplets above 300 microns in diameter, thus meeting the PPO topsize criterta prevtousiy stated.

It is apparent from these atomization studies conducted at $100 \% 10$ ad as well as at reduced loads that the five CWFs in an tsotnermal environment generated similar quality sprays, with the exception of UF62C being slightly finer. It is also clear, comparing atomization data to the laboratory fuel analysis summary (Table 3), that atomizations trends did not correlate with viscosity measurements.

In conclusion, based on the isothermal atomization data generated in this study, it appeared, from an atomization viewpoint only, that all fuels, with the exception of UF62C, would combust with nearly equivalent levels of performance. Higher levels of carbon utilization would be expected from fuel UF62C. 


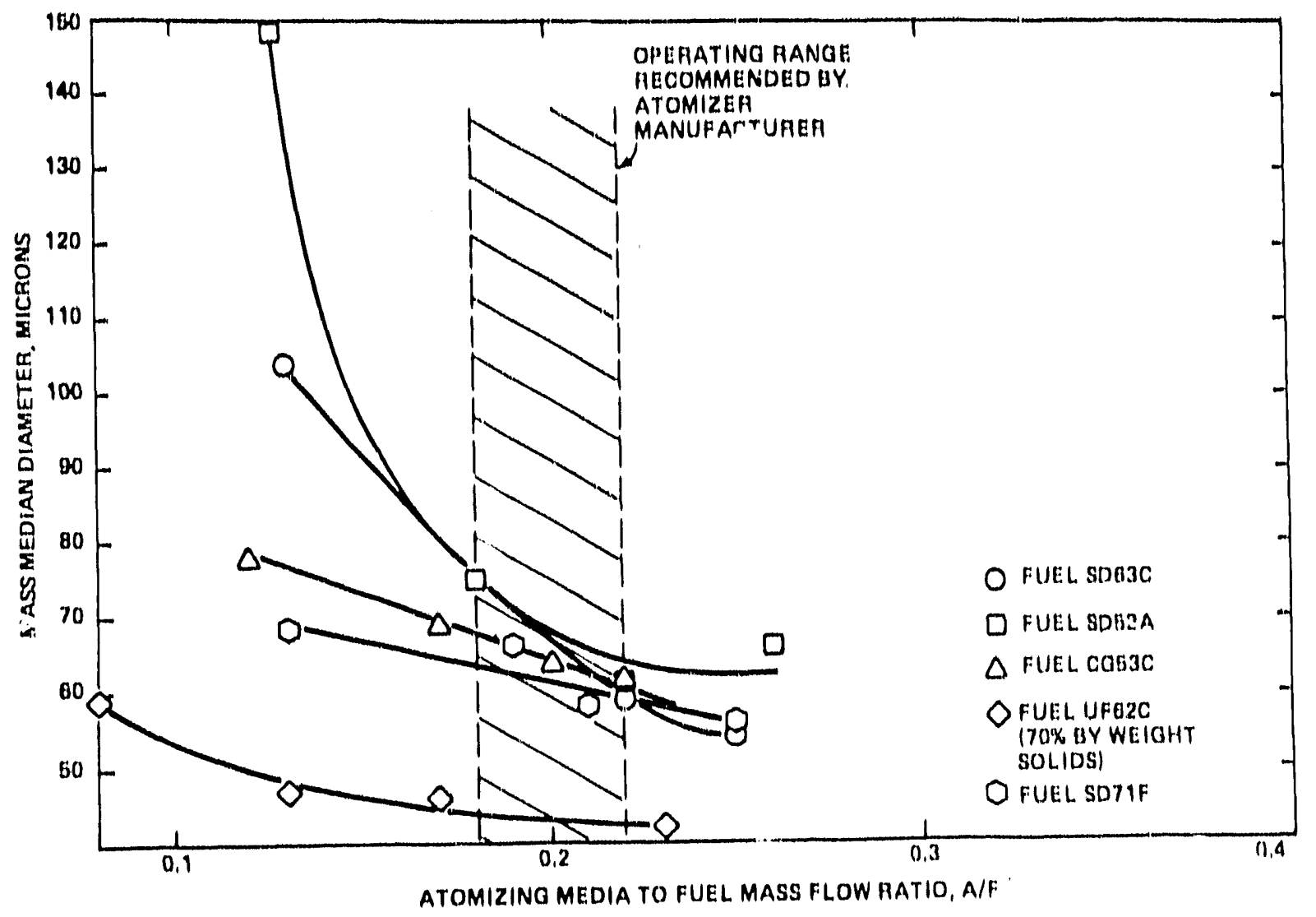

FIGURE 19: SPRAY DROPLET MMD vs A/F RATIOS AT 100\% LOAD 


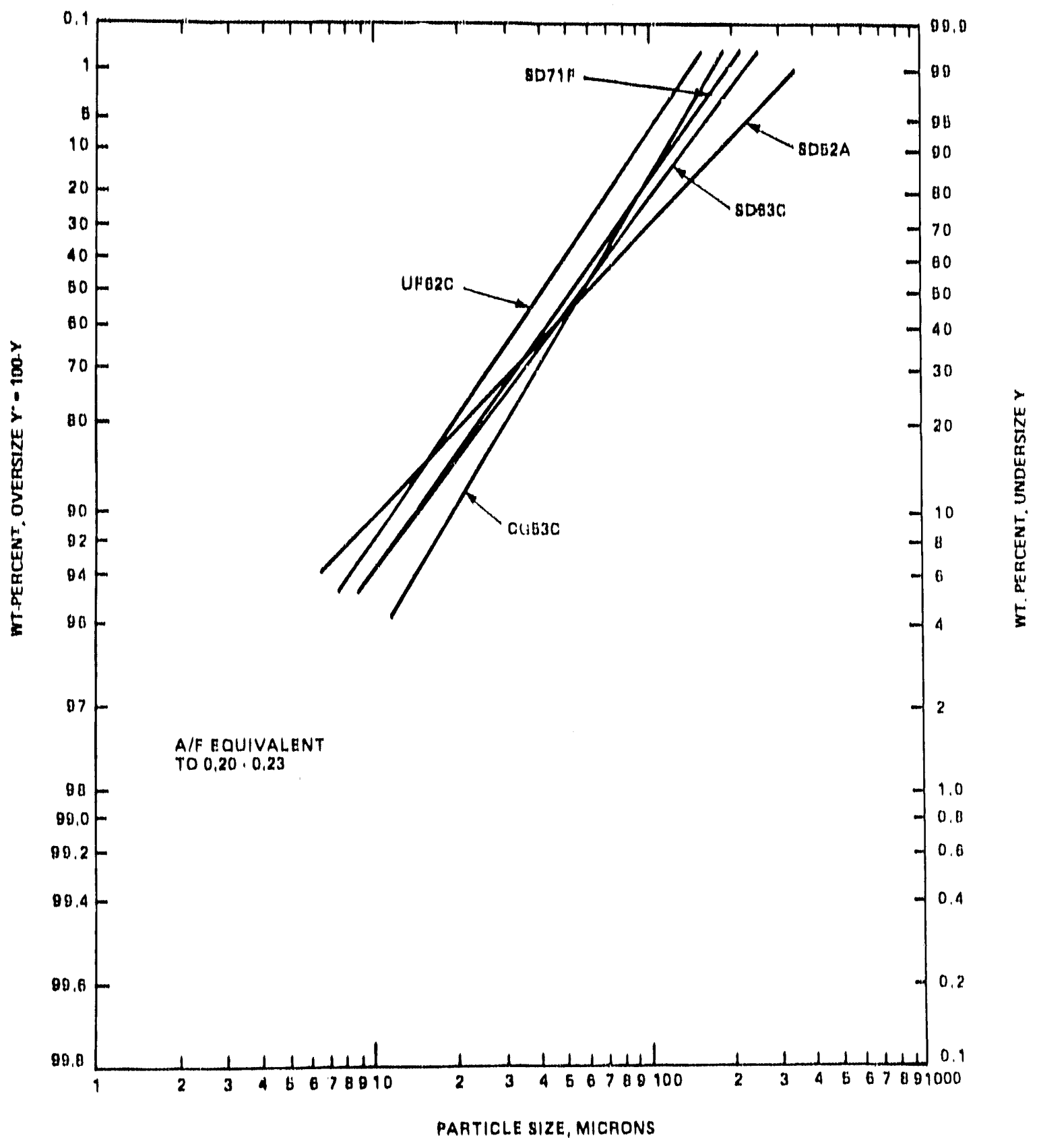

FIGURE 20: SPRAY DROPLET SIZE DISTRIBUTION @100\% LOAD 


\section{$X . \quad$ COMBUSTION CHARACTERIZATION}

Subsequent to atomization characterization, each fuel was subjected to a sertes of detafled parametric firing tests conducted in Combustion Engtneering's Industrial Scale Burner Test Facllity (ISBTF) using the $50 \times 10^{6}$ Btu/hr HSWF burner.

The primary objective of these tests was to ldentify and characterlze relative differences, if any, between the performance of the five CWF's when the fuels were fired in a simulated boller envirorment. Performance differences were quantified thru systematic determination of:

1) Carbon conversion efficiency by flue gas analysis at each test condition.

2) Carbon conversion effictency by particulate analysis at opt imum operating conditions for each load.

3) Flue gas emisstons of $\mathrm{NO}_{X}, \mathrm{SO}_{2}$, and $\mathrm{CO}$.

A) Flame stability and minimum load.

5) Morphology of flyash emissions (scanning electron microscope).

6) Furnace outlet temperatures and peak flame temperatures.

7) The influerice of combustion air temperature on combustion effictency.

8) The effect of varying atomizer $A / F$ ratio on combustion efficiency. 
9) Heat flux along the length of the test facility to determine the heat release profile for each fuel tested.

10) Any fuel specific abnormal handling characteristics, such as atomizer or fuel line pluggage, and fuel settling.

The combustion test matrix developed for this program was designed to evaluate the combustion performance of each test fuel over a wide range of operating firing rates and excess air levels. However, in order to compare the performance of each fuel, it was necessary to hold certain operating variables constant to isolate the effect of fuel on combustion performance. Thus, at each test condition the following burner/ atomizer operating variables were held constant between all of the fuels tested:

1) Atomizer $A / F$ ratio - 0.19-0.21 at $100 \%$ load

$0.39-0.41$ at $50 \%$ load

$0.59-0.61$ at $33 \%$ load

2) Burner Damper Positions

3) Burner Windbox to Furnace Pressure Drop

4) Combustion Air Temperature $\left(500^{\circ} \mathrm{F}\right)$

A complete data set for this test phase is beyond the scope of this report, as a total of 99 individual combustion tests were conducted on the five CWF's. A condensed summary of the data obtained for each of the five CWF's at optimum carbon conversion efficiency levels over the maximum achievable firing rate range is given in Table 4. Note that all fuels, with the exception of SD63A, operated over a 3 to 1 turn down range. Fuel SD63A was 1 imited to a 2 to 1 turn down range. The reason for this is not apparent from a review of either the laboratory fuel characterization study or the atomization study. 


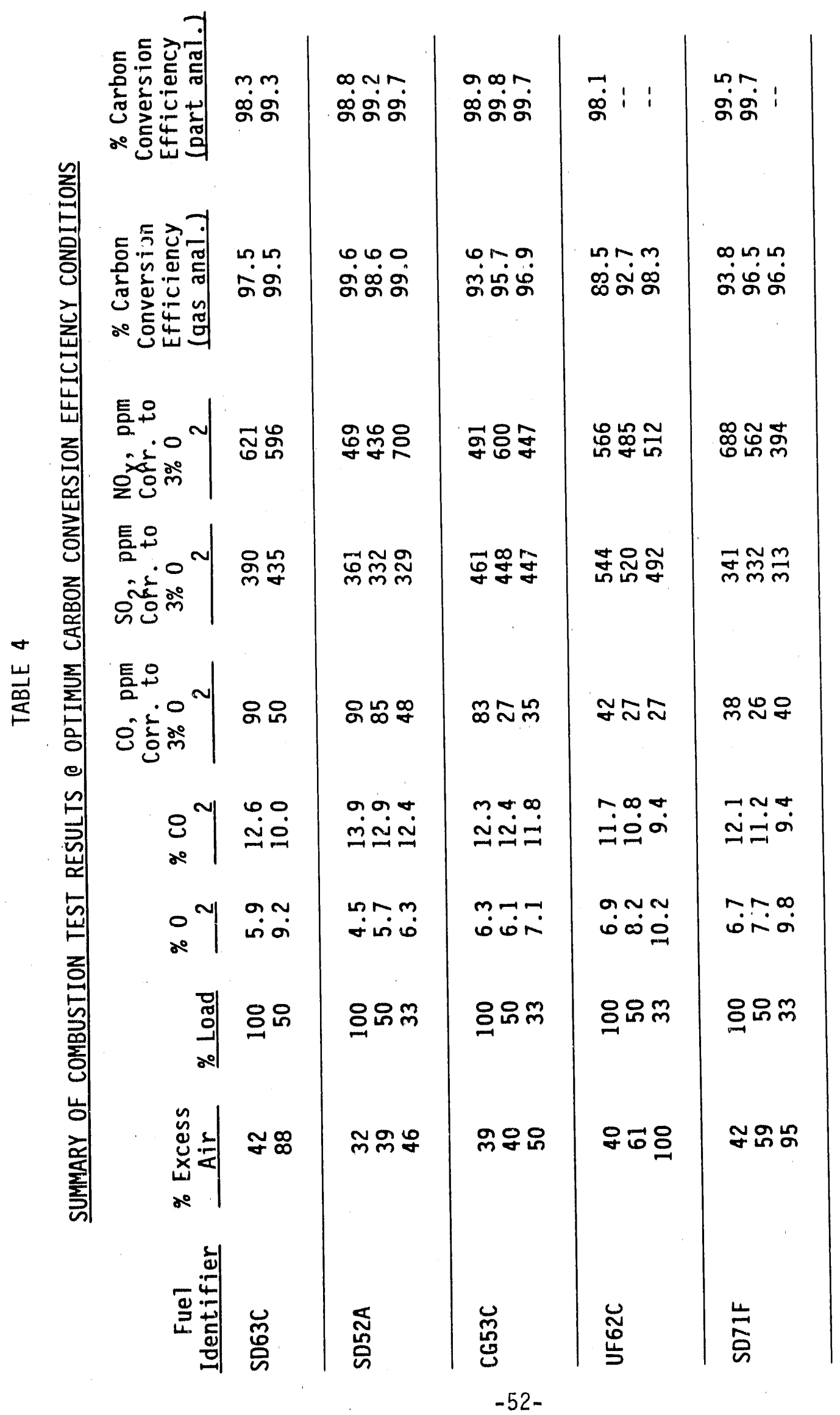


Efficiency data presented in Table 4 is based on flue gas constituent analysis as well as carbon analysis of collected flyash. If one were to look only at carbon conversion efficiency determined by analysis of particulate collected isokinetically (EPA Method 5) from the furnace flue duct, one could conclude that all five fuels were capable of achieving carbon conversions in excess of $98 \%$ at al1 tested loads. However, optimum carbon conversion efficiencies for the five fuels were found to vary over a much wider range $(88.5 \%$ $99.6 \%)$ when efficiencies were calculated from flue gas constituents. The numerical discrepancies between the two efficiency determination methods appear to be due to the particulate sampling techniques. It was noted throughout the test program that several of the fuels had a tendency to generate fairly large "agglomerates".

Photographic evidence of this is presented later in this report. Specifically, fuel UF62C experienced significant agglomeration under combustion conditions. This phenomena has been noted by a number of CWF researchers $(10,11)$. It is theorized that these "agglomerates" may derive from fuel "ligaments" which issue from the nozzle and remain essentially intact in the high temperature furnace environment, rather than breaking down into small, readily combusted, spherical droplets as has been demonstrated during isothermal atomization testing.

While the specific agglomerate formation mechanisms were not identified, it is clear from these tests that a significant population of agglomerates generated by several fuels were not entrained in the combustion gas stream, but rather fell partially combusted to the furnace floor. Flue particulate samples collected for the fuels having agglomerating tendencies did not accurately represent the high carbon percentage material which fell to the furnace floor. For this reason, it is assumed that the carbon conversion efficiency data generated via flue gas analysis represent fuel performance more accurately than do the efficiency data derived 
from collected flue particulate samples. With the above analys is in mind, carbon conversion performance trends presented in this paper will be based on carbon conversion efficiencies derived from flue gas analysis.

Figure 21 summarizes carbon conversion efficiency data obtained at $100 \% 10 a d$ as a function of excess air for the five fuels. In genera1, carbon conversion efficiency improved from all five CWF's with increased excess air. A similar observation was made in the previous comparative burner test program. It is evident in reviewing Figure 21 that the five fuels can be clearly ranked in terms of achievable levels of carbon conversion efficiency. The highest carbon conversions were achieved with fuel SD52A, followed in relative order by fuels SD63C, CG53C, SD71F, and UF62C. The fundamental reasons for the above fuel ranking, after conducting a detailed review of the laboratory fuel characterization data and the atomization characterization study, are not clearly evident.

Most CWF investigators agree that fine fuel atomization is a precursor to good carbon conversion efficiency. The isothermal atomization data indicated that atomization quality for fuels SD52A, SD63C, CG53C, and SD7IF was similar. This result does not correlate with the wide range of carbon conversion efficiencies observed for these fuels. Additionally, fuel UF62C generated the finest sprays, on average, during atomization testing; yet this fuel on average generated the lowest levels of carbon conversion.

Based on these results, it would appear that an isothermal measurement of atomization quality cannot be considered the dominant predictor of CWF combustion characteristics when applied to differing CWF formulations. However, previous investigations have confirmed that isothermal spray quality measurements made on a single CWF formulation can be extremely helpful in predicting the 


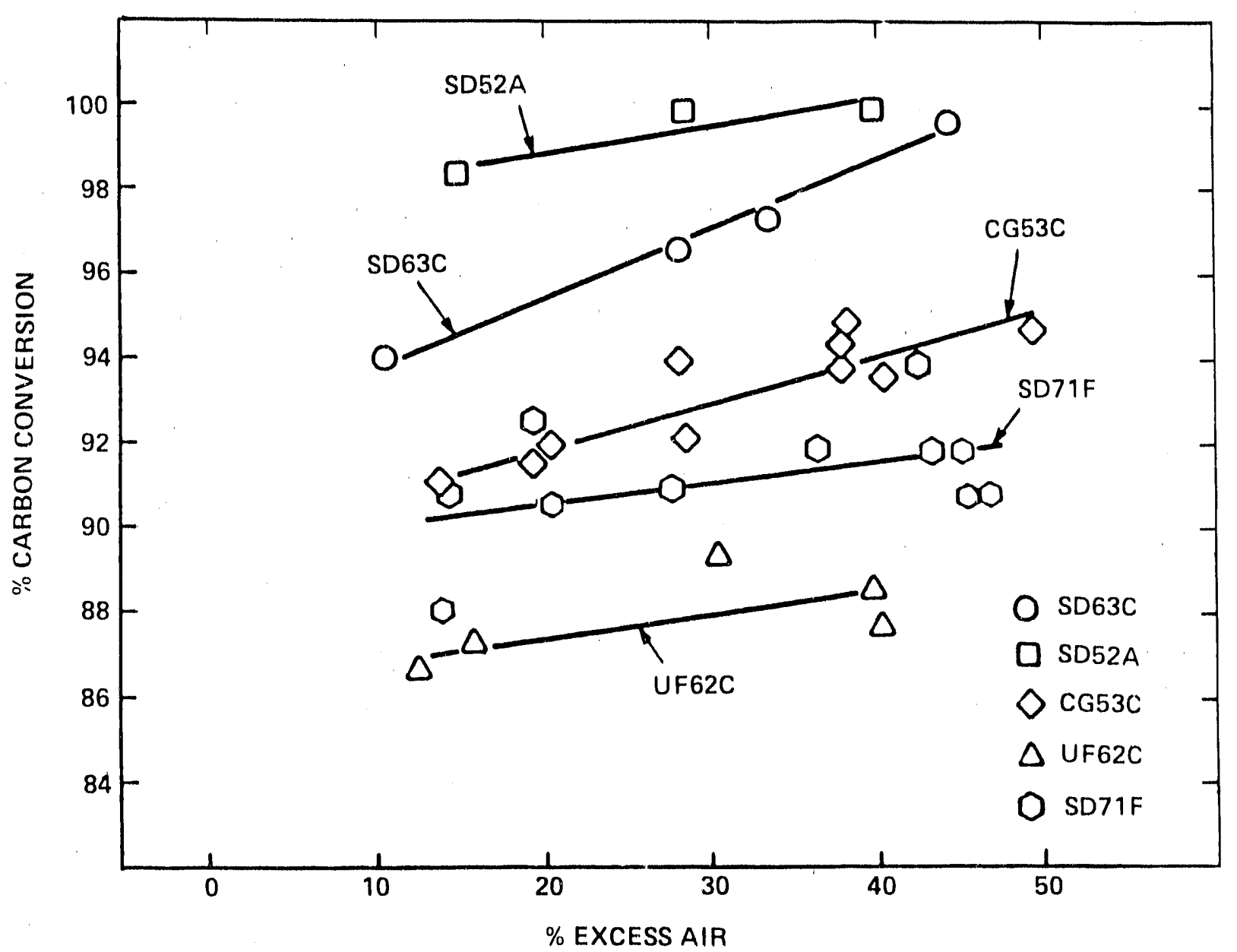

FIGURE 21: EFFECT OF EXCESS AIR AT 100\% LOAD ON CARBON CONVERSION 
combustion performance of CWF. This was true in this study as wel1. Figure 22 presents carbon conversion efficiencies at $100 \% 10$ ad as a function of spray droplet mass median diameter for three of the five CWFs. As previously shown (Figure 19 ), atomizer $A / F$ ratio has a dominant influence on spray quality (droplet mass median diameter). These results show that for fue1s SD63C, CG53C and UF62C, carbon utilization is a strong function of mass median diameter. As MMD was increased, carbon conversion was found to decrease. This observation is consistent with the previous conclusion that isothermal spray quality measurements made on a single CWF formulation can effectively predict CWF combustion performance trends as a function of droplet size distributions.

A number of scanning electron micrographs (SEM's) were taken of collected particulate from the combustion study in an attempt to clarify the inconsistencies noted between each CWF's isotherma? atomization performance and combustion performance. Four representative photographs are shown in Figure 23 for fuel UF62C. The photos show evidence of elungated char particles which are interspersed amongst fine flyash particles. The shape of these char particles seems to support the previously mentioned theory that a certain population of long CWF strands or "ligaments" did not completely atomize in the hot furnace. Rather these ligaments, which contain a number of coal particles, tended to dry and burn as agglomerates. Cold flow atomization data would not predict this phenomenon since it was conducted at a distance (far field) which ensured spherical droplet formation.

Burner flame stability was documented photographically for all five of the fuels tested. The luminous flames produced by all fuels, with the exception of UF62C, were highly stable and attached to the 


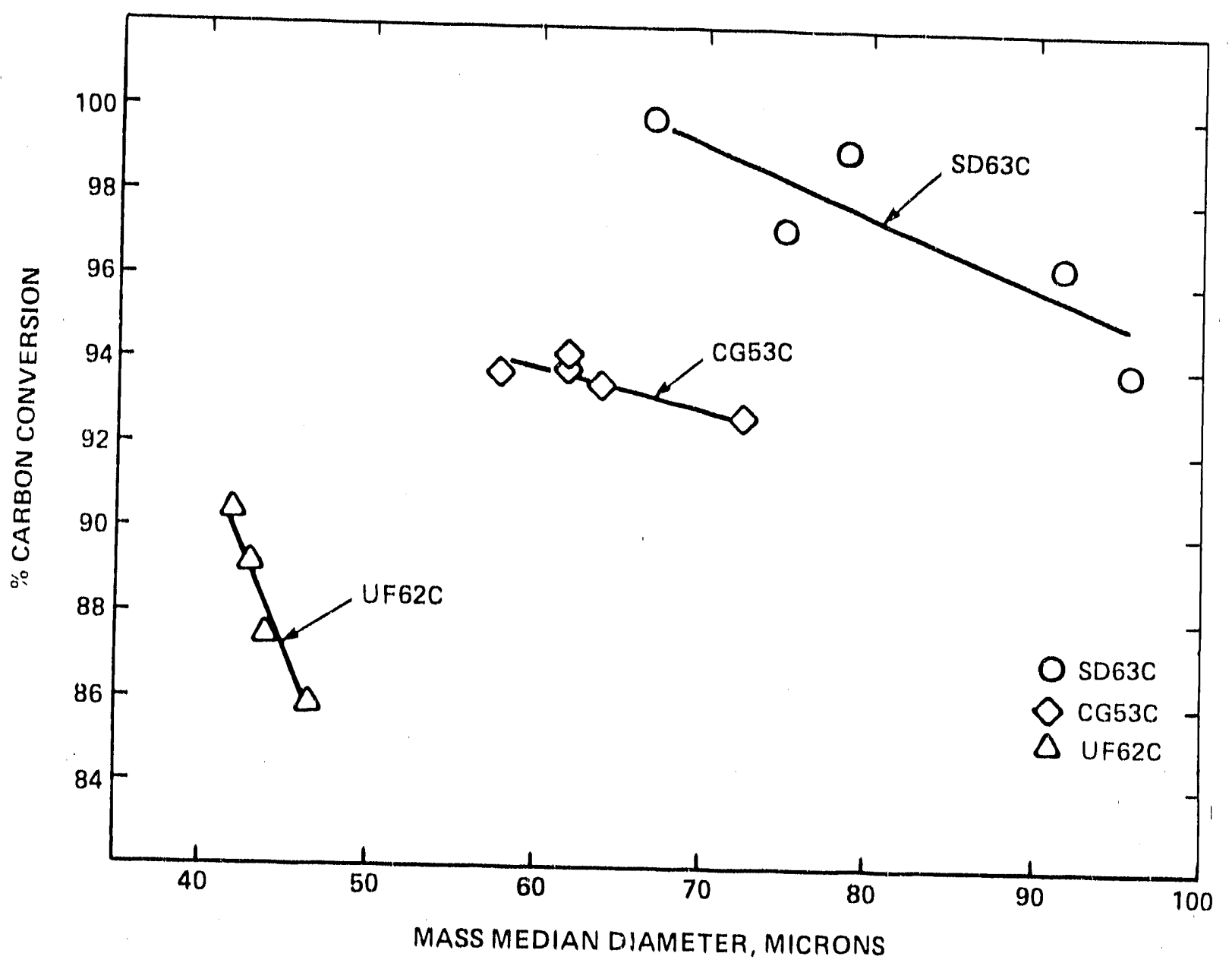

FIGURE 22: EFFECT OF SPRAY DROPLET DIAMETER ON CARBON CONVERSION 


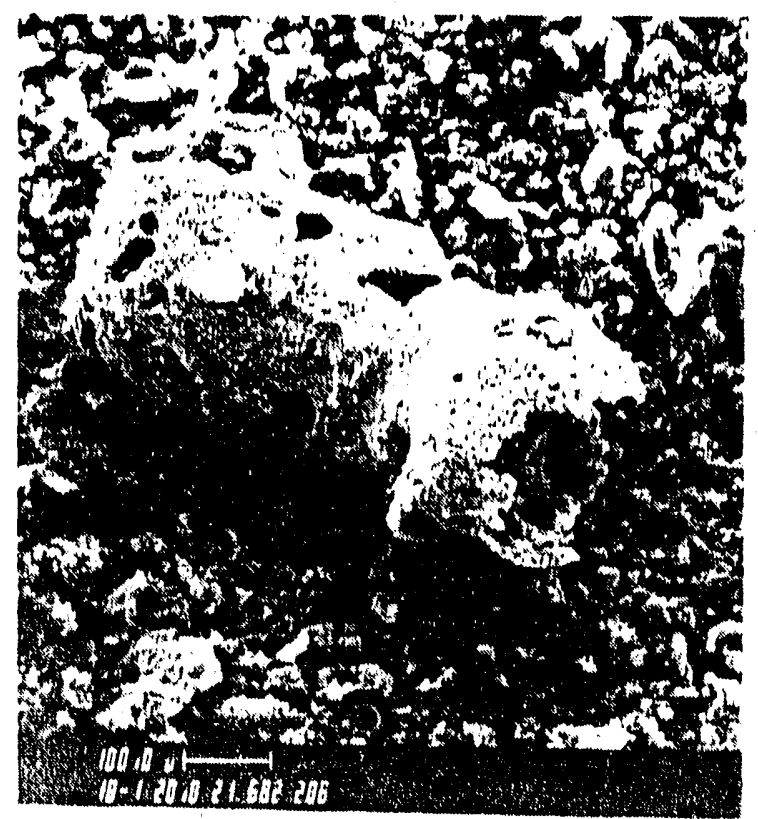

a) $100 \%$ LOAD

$100 X$

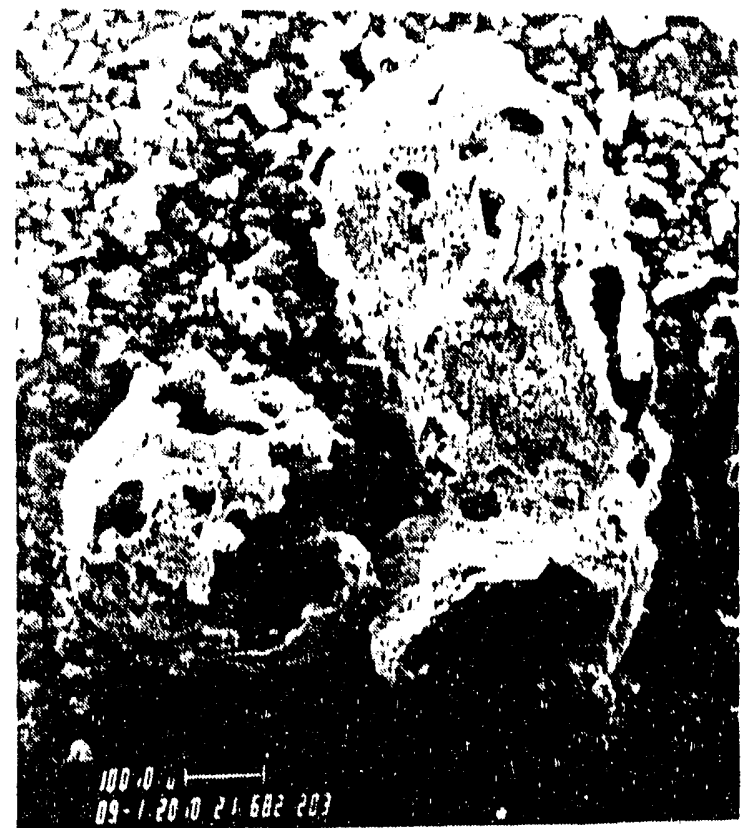

c) $100 \%$ LOAD 90X

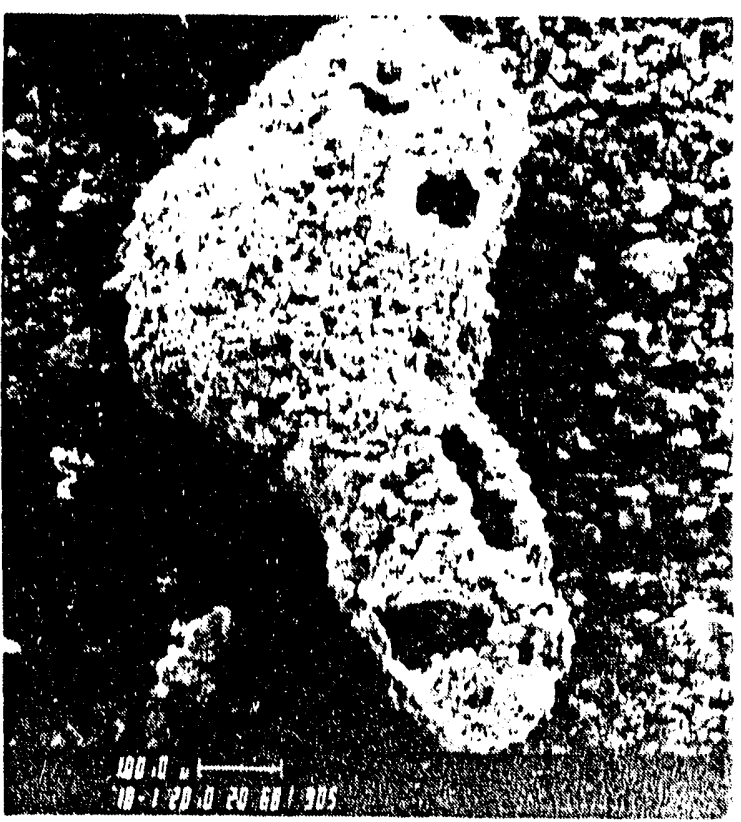

b) 100 LOAD

$100 X$

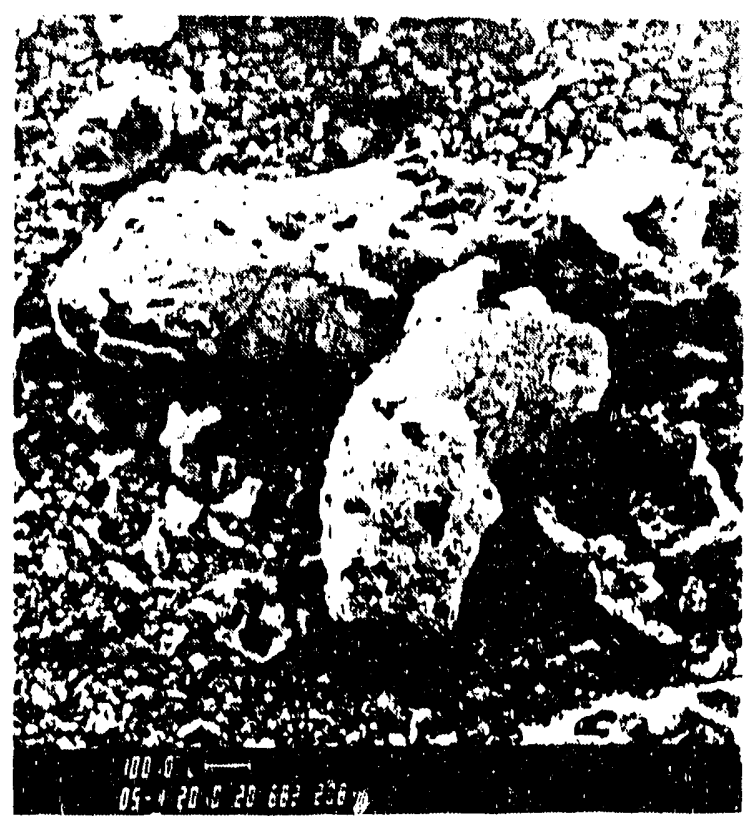

d) $100 \%$ LOAD

$50 X$

FIGURE 23: SCANNING ELECTRON MICROGRAPHS OF FLY ASH FROM UF6.2C CWF 
burner quarl. Good flame stablltty was achieved during inftial testing of UF62C. However, as testing progressed flame stabllity degraded. The source of the degradation was likely varlability in the solids loading for fuel UF62C. Progressive coal settiling was noted in the fuel supply tank during the later portions of the combustion test program.

An interesting flame stability observation was made during the evaluation of SD52A. Flame stability was poor for SD52A when the burner's atomizer was operated at atomizing atr/fuel mass flow ratios of 0.19 to 0.21 at $100 \%$ load. The other four fuels in the program operated successfully at $A / F$ ratios in the 0.19 to 0.21 range. A dramatic improvement in flame stability was achleved when the $A / F$ ratio was reduced to 0.16 for fuel SD52A. An explanation for this anomalous behavior may be found from an analysis of the isothermal atomization data. The percentage of spray droplets exceeding 300 microns tended to increase with fuel SD52A when the atomizer $A / F$ ratio exceeded 0.18 . At an $A / F$ ratio of 0.22 , the percentage of droplets exceeding 300 microns was in excess of $1 \%$. It is possible that ignition stability would suffer as a result of the increased population of large droplets generated when fue 1 SD52A was atomized at $A / F$ ratio's in excess of 0.18 .

The formation of $\mathrm{NO}_{x}$ during combustion is commonly classified in terms of the nitrogen source for the reaction. "Thermal $\mathrm{NO}_{x}$ " refers to $\mathrm{NO}_{x}$ that is formed at high temperatures from nitrogen and oxygen present in the combustion air. $\mathrm{NO}_{x}$ formed in this way has been shown to be function of temperature, $\mathrm{N}_{2}$ and $\mathrm{O}_{2}$ concentrations, and the time of exposure of $\mathrm{N}_{2}$ to $\mathrm{O}_{2}$ at high temperatures. Temperatures in excess of approximately 2800 degrees Fahrenheit are generally required for this process (12). 
"Fuel $\mathrm{NO}_{x}$ " refers to $\mathrm{NO}_{x}$ formed from organtcally bound fue 1 nitrogen. Although the mechantsms of "fuel $\mathrm{NO}_{x}$ " formation are generally not yet fully understood, it is known that its formation is insensitive to flame temperature. Since significant quantities of nitrogen ( 0.1 to 2 percent by weight) can be found in coals, fuel $\mathrm{NO}_{x}$ is a major cintributor to the total $\mathrm{NO}_{x}$ formed. Previous studies have indicated that up to $80 \%$ of the total $\mathrm{NO}_{x}$ can be fuel related. The matn factor affecting the conversion of fuel bound nitrogen to $\mathrm{NO}_{x}$ is oxygen availability.

Extensive furnace temperature mapping data, obtained with a suction pyrometer, indicate that at no time during combustion testing of the five CWF's did flame temperatures exceed the $2800^{\circ} \mathrm{F}$ necessary for thermal $\mathrm{NO}_{X}$ formation. This indicates that the $\mathrm{NO}_{X}$ emtssions measured for all of the fuels were primartly fuel related.

Table 5 summartzes the range of $\mathrm{NO}_{X}$ emtssions measured for each CWF. Note that no attempts were made in this test program to minimize $\mathrm{NO}_{X}$ levels; test guidelines focused on flame stability and carbon converston efficiency. Application of commonly known $\mathrm{NO}_{x}$ control technologies such as "staged combustion" would likely reduce the levels of $\mathrm{NO}_{X}$ observed here.

Sulfur dioxide emisstons, in general, are not a function of burner/ furnace operating conditions. The amount of $\mathrm{SO}_{2}$ generated during the combustion process is directly proportional to the amount of sulfur present in the fuel. Since essentially all (90\% or more) of the sulfur present in the fuel is converted to $\mathrm{SO}_{2}$ and $\mathrm{SO}_{3}$, any increase or decrease in fuel sulfur should result in a corresponding increase or decrease in $\mathrm{SO}_{x}$ emissions. 
TABLE 5

${ }^{\text {NO }} \times$ Emtsstons

$\begin{array}{lcc}\text { Euel } & \begin{array}{c}\text { \% by weight Nitrogen } \\ \text { Centent imotsture free) }\end{array} & \begin{array}{c}\text { Ibs NO } / 10^{6} \text { Btu Fired } \\ \text { Lrange for all firing rates) }\end{array} \\ \text { SD63C } & 1.5 & 0.54-1.13 \\ \text { CG53C } & 1.7 & 0.64-1.06 \\ \text { UF62C } & 1.5 & 0.67-0.95 \\ \text { SD71F } & 1.5 & 0.68-1.06 \\ \text { SD52C } & 1.8 & 0.54-0.97\end{array}$




\section{SUMMAR.' OF TASK 4 RESULTS}

\section{Multiple Burner Test Program}

The subject test program successfully quantified the performance characteristles of four generlcally different CWF burner designs with respect to a predetermined set of Preliminary Performance Object tves (PPOs). A single reference CWF formulation was used throughout testing; this allowed the investigators to draw conclusions about the relattve performance of one burner design to another.

Tests were conducted first on each burner's fuel atomizer. These tests defined spray droplet size distribution and general droplet ballistics characteristics. All tests were conducted in a non-combustion environment using nun-intrusive optical instrumentation.

Comparative combustion tests on the atomizer/burner register systems followed. These tests were conducted in a facllity designed to simulate a botler environment whtch represented a typtcal ofl to CWF retroftt situation.

A11 of the burner systems in the program were capable of firting the reference CWF formulation. Each burner configuration tended to exhibit unique perforinance characteristics which can be attributed to fundamental differences in each burner's atomization properties and/or near-fleld thermal/aerodynamic characteristics. Table 6 summarizes the relative performance of each burner system design with respect to the Preliminary Performance Objectives. It is clear upon examination of Table 6 that in many cases the burners evaluated met or exceeded PPO levels of performance. 
离

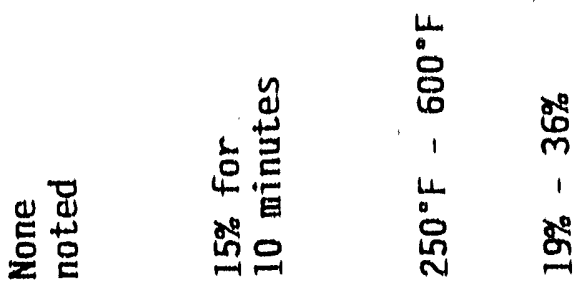

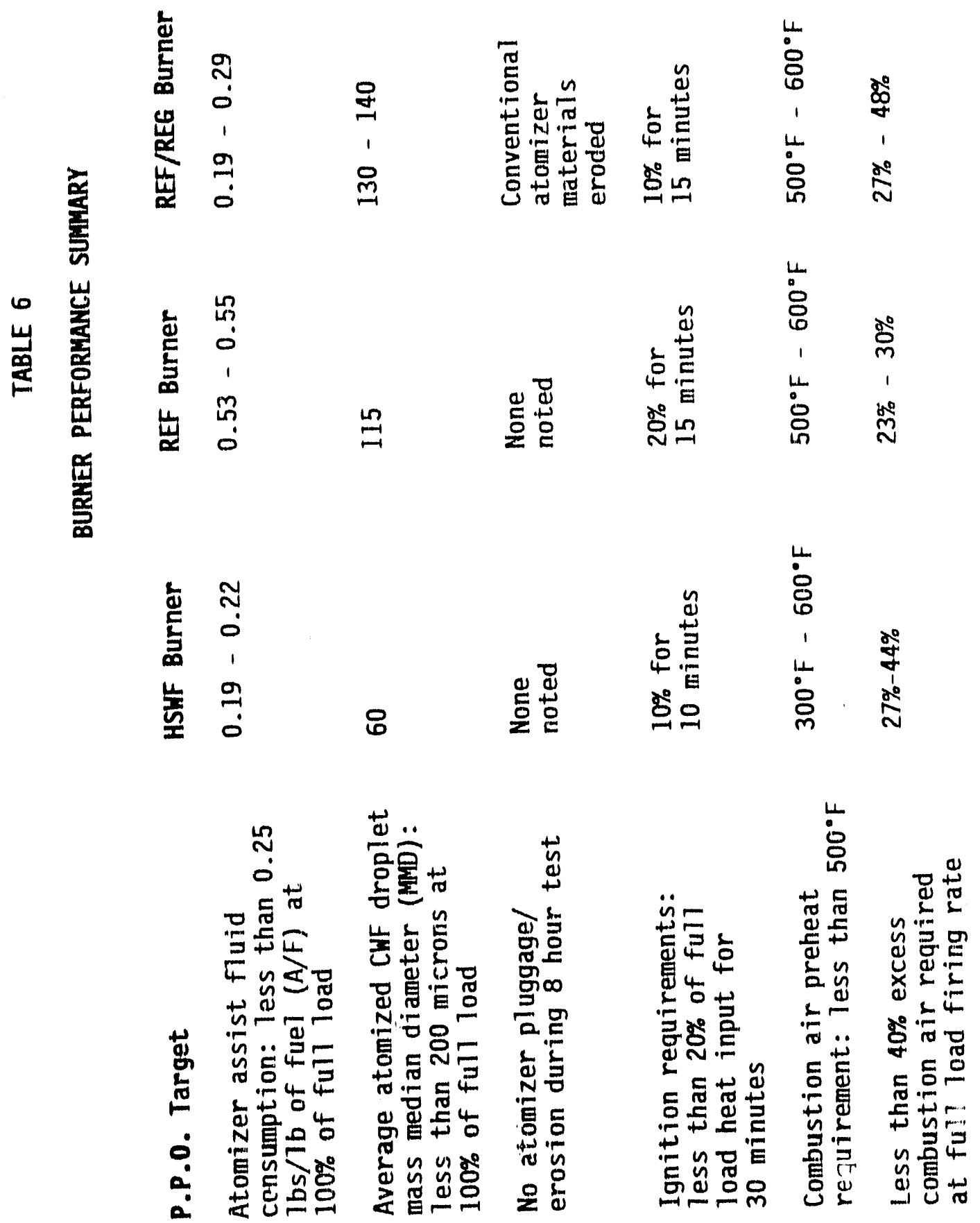



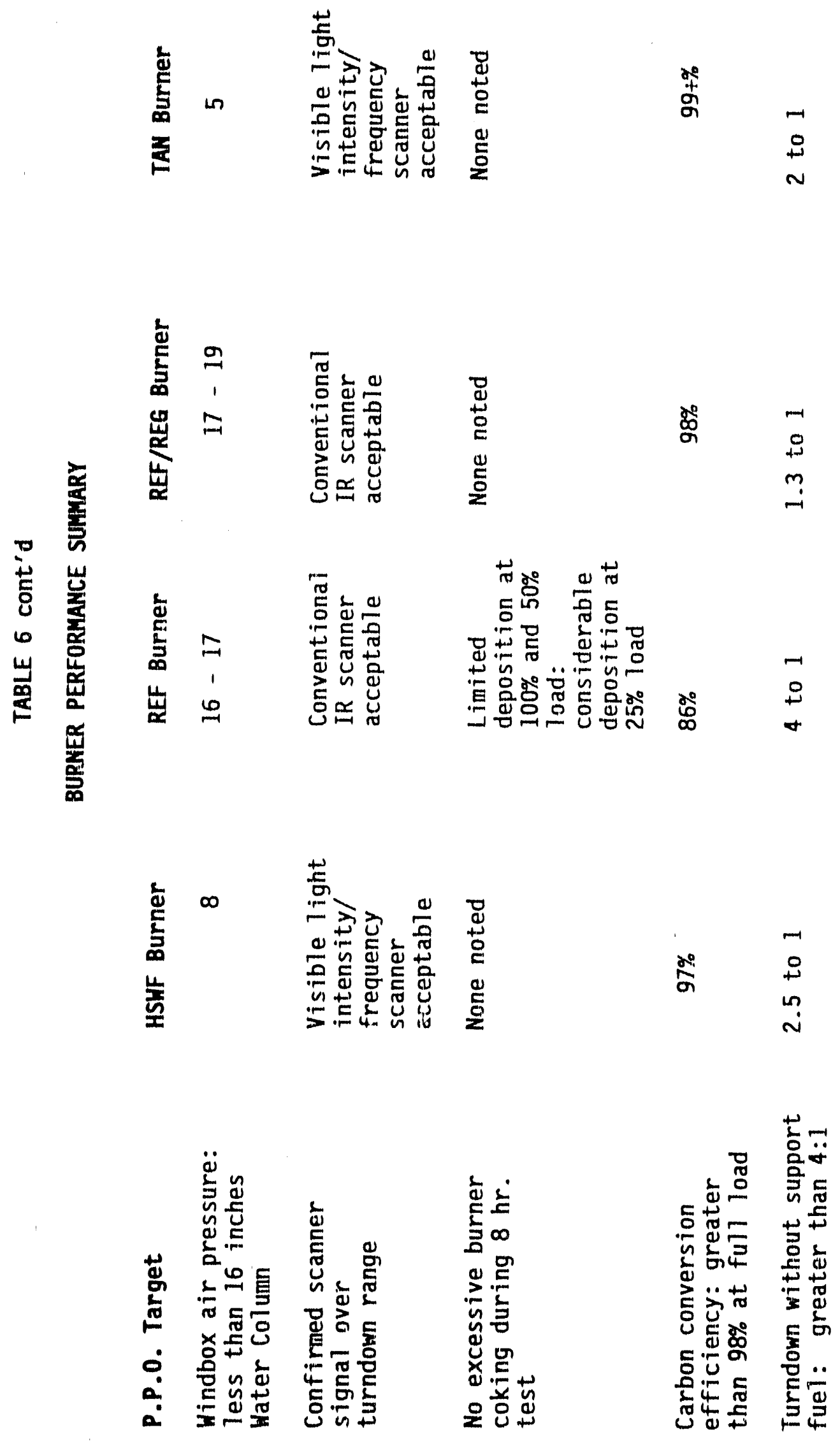